\title{
Historiografía del arte prehistórico en la Península Ibérica: I, hasta 1914
}

\author{
Eduardo Ripoll Perelló*
}

\begin{abstract}
RESUMEN ZUSAMMENFASSUNG
Historiografía del arte rupestre de la Península (hasta 1914), en relación con el de otras regiones cercanas. Antecedentes en la literatura y la arqueología. Significado del descubrimiento y valoración del arte mueble del Paleolítico Superior en Francia. La cueva de Altamira, su descubridor M. Sanz de Sautuola y las polémicas a que dió lugar su descubrimiento.

La revaloración de la cueva de Santillana por H. Breuil y

E. Cartailhac. La actividad exploradora de H. Alcalde del Rio (con la lista de sus descubrimientos).

El reconocimiento y valoración de las diferentes facies del arte ruprestre postpaleolítico peninsular.

Historiographie der Höhlenkunst der Iberischen Halbinsel (bis 1914), in Beziehung zur Höhlenkunst anderer benachbarten Gebiete. Vorkenntnisse der Literatur und der Archäologie. Bedeutung der Entdeckung und Einschätzung der Hochpaleolithiscen mobilen Kunst in Frankreich. Die Höhle in Altamira, ihr Entdecker M. Sanz de Sautuola und die durch seine Entdeckung verursachten Streitgespräche. Revalorisierung der Höhle in Santillana von H. Breuil und E. Cartailhac durch geführt. Die Expeditionen von H. Alcalde del Río (mit der Auflistung seiner Entdeckungen). Anerkennung und Einschättzung der verschiedenen Aspekte der postpaleolithischen Höhlenkunst der lberischen Halbinsel.
\end{abstract}

* Profesor emérito de la UNED. 
El presente trabajo retoma en parte y amplía mucho uno escrito hace más de veinte años ${ }^{1}$. Con él queremos trazar una sucinta historia de los descubrimientos de arte prehistórico en la Península lbérica en sus dos grandes etapas: la paleolítica y la postpaleolítica (ésta con sus tres facies: levantina, esquemática y de los petroglifos galaicos). Se prestará también alguna atención a los de nuestro ámbito geográfico inmediato, muy especialmente los de Francia, por su evidente relación.

El conocimiento científico de las manifestaciones del más antiguo arte de la humanidad en el Sudoeste de Europa cuenta con algo más de un siglo y medio de investigaciones que se desarrollaron primero de una forma muy lenta y sólo referidas al arte mueble, pero que alcanzaron su pleno auge al ser reconocida la autenticidad de Altamira y al producirse en Francia y España el hallazgo de importantes cuevas con arte, además de individualizarse las varias fases del arte postpaleolítico peninsular. A ello hay que sumar - también por lo que pudieran tener de estímulo- los avances en el conocimiento de la existencia y complejidad de un arte rupestre de muchos pueblos "primitivos", actuales o subactuales (con frecuencia calificado como "exótico", por ejemplo el de los bosquimanos, el de antiguas poblaciones norteafricanas, o el de ciertas regiones de América) ${ }^{2}$. Pero hay asimismo en este aspecto un capítulo europeo muy importante: nos referimos al arte rupestre escandinavo en cuyo estudio, muy adelantado a su tiempo, sobresalió el "anticuario» Carl-Georg Brunius (1792-1869). Con todo ello, queremos subrayar que fuera del espacio geográfico del que aquí nos ocuparemos, en Eurasia, África y América, las noticias sobre hallazgos de arte rupestre en los siglos XVII, XVIII y XIX son abundantes, aunque casi siempre van acompañadas de fantasías y de hipótesis peregrinas. A partir de mediados del ochocientos, se avanza en estos estudios y cuando se llega a los años del cambio de centuria se producen ya logros sustanciales y fundamentales ${ }^{3}$.

E. Ripoll Perello, "Síntesis de la historia de los descubrimientos de arte prehistórico y su problemática", Sautuola (Santander), III, 1982, págs. 9-21 (escrito en 1976). Una parte de dicho texto, pero sin aparato bibliográfico, se publicó en Historia-16, n' 10, febrero de 1977, págs. 70-76. También nuestra colaboración en (J. García CAStro, ed.), Arte rupestre en España, Madrid, Zugarto, 1987, págs. 8-15.

2 Noticias sobre dichos avances en los volúmenes de L'Anthropologie de aquella época, por ejemplo III, 1892, págs. 145 y ss., XV, 1904, págs. 133, 247-248, etc.

3. Para las regiones "clásicas" del Viejo Mundo: H.-G. BANDI (ed.), L'Âge de la Pierre, quarante millénaires d'art pariétal, París, A. Michel, 1960, 242 págs., con figuras. De él, citaremos ahora los capítulos de Henri LHOTE, "L'Art rupestre de l'Afrique Mineure et du Sahara" (págs. 92147); Erik HoLm, «L'Art pariétal de l'Afrique australe» (págs. 149-198); y Andreas LoMmel, "L'art rupestre australien" (págs. 199-223). Para África, anteriormente: F. CHRISTOL, Au sud de l'Afrique, París, 1898. Historia de la cuestión: Leo Frobenius y Henri BreulL, Afrique, París, Cahiers d'Art, 
Dividiremos nuestro trabajo en dos partes. Las separamos en el momento traumático que para nuestra ciencia fue la Primera Guerra Mundial. Para la segunda parte, el relato se hará más conciso y con menor número de detalles, pues la profusión de investigaciones y descubrimientos, con sus correspondientes publicaciones, harían necesario un número de páginas muy superlor al aquí disponible ${ }^{4}$.

\section{ANTECEDENTES}

Existen ciertos indicios de que el arte rupestre prehistórico «fue visto" en algunas ocasiones por gentes de tiempos posteriores a los de su creación. Además del ambiente de misterio propio de las cavernas, la presencia de representaciones en los muros de las cavidades tuvo que llamar la atención y sorprender a los que a ellas se atrevían a entrar.

Aunque seguramente se descubrirán otras, citaremos el caso de la cueva de La Griega (Pedraza, Segovia), en la que más de un centenar de representaciones paleolíticas grabadas están acompañadas de multitud de grafismos producidos por visitantes posteriores. Entre ellos destacan los que escribieron en latín textos de carácter votivo o religioso (siglos I a III de la era). El propio ambiente de oscuridad y silencio en las entrañas de la tierra podría inducir a ciertas ceremonias de las que los grafitos son testimonio (igual ocurre en la cueva de Román, en Clunia, Burgos). Pero, el visitante -o peregrino- de La Griega no podía dejar de ver sus notables figuras de équidos paleolíticos ${ }^{5}$. En esta cueva segoviana es indudable que no se trata de la supervivencia de un culto. En cambio, la continuidad de ciertos ritos está atestiguada en los letreros ibéricos y latinos grabados en elfriso levantino al aire libre de Cogul (Lérida) ${ }^{6}$.

1930. Para América, la más reciente obra de conjunto es: Juan SCHOBInger, Arte prehistórico de América, México, Consejo Nacional para la Cultura y las Artes, 1997, 289 págs., con abundante ilustración y bibliografía (ed. italiana, Milán, Jaca Book, 1997). Acerca del tema del arte rupestre en el Nuevo Mundo, establecimos una síntesis en: E. RIPOLL PERELLó, "El arte rupestre en América", en (Jorge JuAn EIROA, ed.), // Curso de Prehistoria de América hispana, Murcia, Universidad, 19921993, págs. 39-63 (con bibliografia).

${ }_{4}$ En ningún modo este trabajo podría considerarse exhaustivo. Esta primera parte se refiere a los antecedentes y a las investigaciones hasta 1914. La segunda parte aparecerá en el próximo volumen de ETF.

5 M. SOLEDAd CORChón, et al., La cueva de La Griega de Pedraza (Segovia), Zamora, Junta de Castilla y León, 1997, 280 págs., 263 figs. y 2 hojas plegadas. En particular el capítulo de M. MAYER y J.-A. ABASOLO, “Inscripciones latinas», págs. 183-259.

6 Martín Almagro BASCH, El covacho con pinturas rupestres de Cogul (Lérida), Lérida, Instituto de Estudios llerdenses, 1952, en especial págs. 43-47. 
Mucho menos claro es el caso del buscador de tesoros que se movió por la cueva de Las Monedas (Puente Viesgo, Cantabria) y que en una pequeña sima del fondo de la caverna perdió su bolsa con 23 piezas de cobre y una de plata, la más moderna de las cuales corresponde al reinado de Felipe II (1503). El hallazgo del pequeño lote monetario dio nombre a la cavidad ${ }^{7}$. Las huellas del osado explorador no se identificaron en la pequeña sala de las pinturas, lo que hace suponer que seguramente no llegó a verlas.

Existen también algunas citas escritas que, antes del siglo XIX, no alcanzan otra categoría que las de simple curiosidad erudita al no poder tener sus autores conciencia de lo que luego sería ciencia de la Prehistoria. Así, por ejemplo, tenemos noticia de las ceremonias de que habló San Paciano (obispo de Barcelona, siglo Iv) en su desconocida obra Cervulus, pero que reprodujo en parte en su Paraenesis. Se trata de una diatriba contra las costumbres de los barcinonenses que, con motivo del año nuevo, se disfrazaban de animales; costumbres de las que se sabe todavía existían en el siglo VII (condenadas por el Concilio de Toledo del año 633). Su editor, Lisardo Rubio, sintetizó así el relato de San Paciano:

«Los hombres se disfrazaban de mujeres y viceversa; y con mayor frecuencia unos y otras se disfrazaban de animales (ciervo, cierva, cabra); bajo tales disfraces conseguía los mayores aplausos quien mejor remedara los instintos más bajos de los animales representados y pronunciara palabras 0 canciones más obscenas" ${ }^{8}$.

Del mismo orden, acaso como aquel más cerca del folklore que de la historia ${ }^{9}$, cabe recordar el hecho de que en el siglo xv el Papa Calixto III Borja condenara los ritos heréticos que se practicaban en la ruralia de Valencia en "cuevas con caballos» ${ }^{10}$. Es posible que en esta misma categoría debamos incluir la alusión a cuevas y figuras en unos versos de la segunda parte del Quijote (1615) que dicen así:

«En las cavernas lóbregas de Dite,

Donde estaba mi alma entretenida

\footnotetext{
7 E. Ripol Perelló, La cueva de Las Monedas en Puente Viesgo (Santander), Barcelona, Instituto de Prehistoria y Arqueología y Wenner-Gren Foundation, 1972 (trad. al inglés, 1980).

8 Lisardo RubIo FERNÁNDEZ (introd. y ed.), San Paciano, Obras, Barcelona, Universidad, 1958, págs. 9-12.

${ }_{9}$ No entraremos en este trabajo en el rastreo de ideas y hechos que pueden retrotraerse al mundo prehistórico en el folklore actual o subactual, labor difícil pero que bien merecería una investigación a fondo.

10 Josep Rius Serra, Registro ibérico de Calixto III, 2 vols., Barcelona, 1948 (textos de los años 1455 a 1457). Dato que no hemos podido comprobar.
} 
En formar ciertos rombos y caráteres,

Llegó la voz doliente de la bella

Y sin par Dulcinea del Toboso...» ${ }^{11}$.

Con mucha más seguridad, la más antigua noticia que tenemos sobre la existencia de arte parietal prehistórico es la de François de Belleforest, que en su Cosmografia, impresa en 1575, hace referencia a las figuras de la ahora bien conocida caverna de Rouffignac, también llamada Cro du Cluzeau o Grotte de Miremont (Dordoña). Al dorso de su magnífico mapa de la diócesis de Sarlat, Belleforest escribe:

«On monstre une caverne qui n'est pus beaucoup esloignée de la ville de Miraumont, que les habitants appelent Le Puzeau. Ceux qui y sont entrez ont accoustumé de reconter des merveilles: disant qu'elle s'etend sous terre 5 . ou 6 . lieues, y ayant de fort belles sales \& chambres, ornées \& tapissèes de pierres marquetèes, des autels, \& des Peintures en plusieurs lieux, monstrant aussi les vestiges de tourte sorte de bestail, des fontaines \& des rivieres...» ${ }^{12}$.

Otro texto de la misma época, debido a la pluma de Lope de Vega, tampoco es muy claro, aunque personalmente nos parece que alude al arte rupestre. Se trata de un fragmento de su obra Las Batuecas del Duque de Alba, escrita en 1598 e impresa en 1633, que dice así:

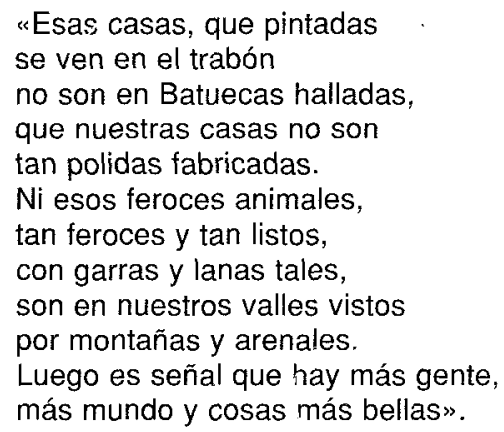

Estos versos fueron exhumados en 1909 en un artículo del erudito placentino Vicente Paredes (1840-1916) que se publicó en la Revista de

\footnotetext{
11 Miguel DE Cervantes, El ingenioso hidalgo Don Quijote de la Mancha, 2. parte, cap. XXXV. Citamos por la edición de Francisco Rodriguez Asin, vol. IV, Madrid, La Lectura, 1913, págs. 326-327.

12 François DE BELLEFOREST, Cosmographie universelle de tout le monde, París, M. Sonnius, 1575, texto en la pág. 268. Lo reproducen otros autores del siglo XVIII. Sobre el interés que siempre despertó la caverna: B. y G. DeILUC, "La grotte de Rouffignac: un plan de 1814», Bulletin de la Société Historique et Archéologique du Périgord, CXIV, 1987, págs. 255-257, 2 figuras.
} 
Extremadura ${ }^{13}$. Se refiere al notable y peculiar núcleo de arte esquemático de Las Batuecas (Salamanca) y son probablemente - dejando de lado el citado texto cervantino- la noticia más antigua sobre el arte prehistórico peninsular. $V$. Paredes también se refirió a otros textos sobre este lugar, siendo especialmente importante el del viajero Antonio Ponz del que se hablará más adelante.

Otra noticia erudita es la que recogió el cronista portugués Jerónimo Contador de Argote en sus obras publicadas entre 1734 y $1738^{14}$. En ellas se refiere a las «letras» rupestres pintadas en una roca del lugar llamado Cachão da Rapa (Anciaes, Tras os Montes). El texto correspondiente a la primera de sus obras dice así:

«Perto pois do Cachão da Rapa, na margem direita do río Douro, que he precipitada em distancia de vinte passos do rio, está eminente hum penhasco todo cuberto de musgo, excepto en parte de huma face que está muy lisa por espaço de dos covados em alto, e quatro em largo no meyo, nas extremidades tres; nesta tal face lisa se ven debuxadas diversas figuras com cores diversas, a saber: huns quadrados, e outras, que se não póde ben julgar se sao jeroglificos ou letras. Os quadrados en parte se parecem como os do jogo de xadres, en parte differem, porque nem são tantos, nem de dua cores, nem brancos e negros, mas só de una cor que he hum vermelho escuro, a margem porém em huns he azul, outros a não tem. As demais figuras se compoem das mesmas duas cores. O vulgo, e, o que mais, alguns homens nobres, o eruditos, entendem que estas figuras se renovão todos os annos em dia de S. João Bauptista pela manhãa, e que apparecem mas brilhantes: eu reputo isto por allucinação da vista» ${ }^{15}$.

La noticia fue simplemente reiterada desde mediados del siglo XIX, hasta que fue destacada como de carácter prehistórico por J. Leite de Vasconcellos en su obra Religiōes da Lusitania. En 1930, J. R. dos Santos Júnior «redescubrió» el lugar, noticia que apareció en los periódicos y de la que se hizo eco H. Breuil. El autor portugués publicó su estudio en 1933 y Breuil, en el primer tomo de su gran obra sobre el arte esquemático, se limitó a recoger

\footnotetext{
13 Vicente Paredes, «De la Sociedad Excursionista Extremeña y algo de Prehistoria de Extremadura", Revista de Extremadura, XI, 1909, págs. 418-427 y 433-442.

14 Jerónimo CONTADOR DE ARGOTE, Memorias para la historia eclesiastica do Arcebispado de Braga Primaz das Espanhas, Lisboa, 1734, t. II, págs. 486-489. ID., De antiquitatibus Conventus Bracaraugustani, libri quator, vernáculo latinoque conscripti... Lisboa, 1738, cap. VII, págs. 232234 del tomo IV (bilingüe). En ambas obras figura el grabado que aquí reproducimos.

15 Copiamos la transcripción que del texto de Contador de Argote hizo J. LEITE DE Vasconcellos, Religióes da Lusitania, Lisboa, Impr. Nacional, 1897, vol. I, págs. 360-363, figs. 76 y 77 (hace también referencia a las primeras noticias modernas). Pero, aunque señaló su carácter prehistórico, Leite de Vasconcellos no se decidió a dar una atribución cultural concreta a las figuras, aunque adujo diversos paralelos.
} 


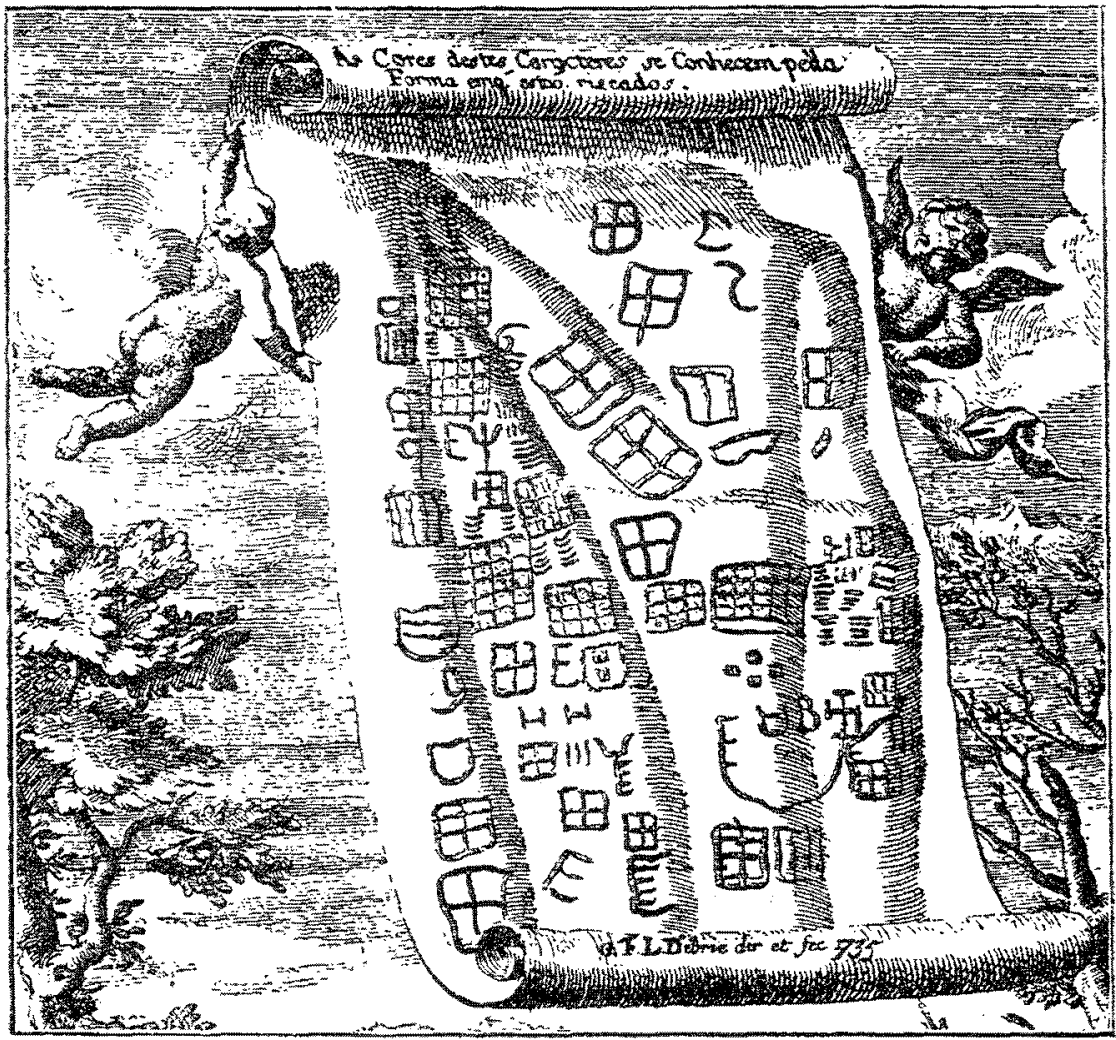

Las pinturas del Cachão da Rapa (Anciaes, Tras os Montes), según J. Contador de Argote (1734)

de nuevo aquella noticia, reproduciendo el texto y el grabado de Contador de Argote, así como a señalar algunos paralelos ${ }^{16}$.

Igualmente a comienzos del siglo XVIII corresponde otra referencia al ya mencionado lugar con pinturas de Las Batuecas. Lo dio a conocer

16 Leite de Vasconcellos, Religióes da Lusitania, citado. Tradujo con más amplitud los textos de Contador de Argote el polígrafo Marcelino MEnEndez PELAYo, Historia de los heterodoxos españoles, Madrid, V. Suárez, 1911, t. I, págs. 97-99. H. BreulL, "Cachão da Rapa, retrouvée", L'Anthropologie, XLI, 1931, pág. 431. J. R. DOS SANTOS JúnIOR, "As pinturas prè-históricas do Cachão da Rapa», Trabalhos da Sociedade Portuguesa de Antropologia e Etnologia, VI, 1933 (separata de 44 págs., 11 figs., 9 láms. y 1 hoja plegada). Su valoración en Henri BrEUIL, Les peintures schématiques de la Péninsule lbérique, t. I, Au nord du Tage, Lagny, 1933, págs. 43-46, figs. 25-26, que sigue a Leite de Vasconcellos y reproduce en parte el texto de Contador de Argote. 
Antonio Ponz en su Viage de España (1728) ${ }^{17}$. Mas de la mitad del tomo VII de su obra está dedicado a Extremadura. Dentro de dicho volumen, la "carta VIII" se ocupa del que llama «país de las Batuecas". Ponz no visitó aquella comarca, pero transcribe un largo escrito de gran interés geográfico que a su atención escribió "aquel nuevo amigo de esta ciudad» (Plasencia) ${ }^{18}$. En él se intercala el parágrafo siguiente:

«Se pasa el rio debaxo del que llaman Sepulcro del Rey Don Sebastián, y caminando ácia el convento, se ve un sitio que llaman el de las cabras pintadas, porque en las peñas que están tan perpendiculares como paredes de casas con sus esquinas, y ángulos rectos, se veian ciertas figuras muy mal hechas por los pastores con almazarrón, en que parece quisieron representar cabras. También se dice que años ha se leía este letrero: quien esta tierra haya de habitar, en cabras y colmenas ha de tratar. Es muy trabajoso subir á dicho sitio de las cabras pintadas» ${ }^{19}$.

Este texto de Ponz también fue recogido y valorado por Vicente Paredes en su artículo citado. En él afirma haber comprobado con seguridad la existencia de las pinturas, aunque, personalmente, a causa de sus muchos años, no había visitado el entonces remoto pequeño valle ${ }^{20}$.

Podemos decir que se acercó más a la «identificación», en 1783, el Licenciado Fernando José López de Cárdenas (1719-1786), párroco de la villa de Montoro, que popularizó el nombre de "Cura de Montoro". Se trata de la Disertación que este erudito envió al Conde de Floridablanca acerca de las pinturas esquemáticas, que él llama "jeroglifos de gentiles», halladas en la comarca de Fuencaliente (Peña Escrita y La Batanera).

Al cumplirse el bicentenario de dicho descubrimiento, el Museo de Ciudad Real organizó una exposición que presentaba, entrę otros, los dibujos de López de Cárdenas, publicando también un muy completo opúsculo de Gratiniano Nieto Gallo con la reproducción de aquéllos y en el que el autor da cuenta del resultado de sus pesquisas en el archivo de la Real Academia de la Historia ${ }^{21}$.

17 Antonio Ponz, Viage de España, t. VII, Madrid, 1728 (2. ${ }^{\circledR}$ ed., 1784), 258 págs., con varias láminas. Usamos la edición facsimil sin comprobar si los textos aquí aludidos ya se encuentran en la primera edición.

18 Ponz, Viage de España, citado, págs. 196-222.

19 Ponz, Viage de España, citado, págs. 203-204. La inscripción, probablemente del siglo XVII, fue vista y copiada por E. Hernández-Pacheco y F. Benítez Mellado. En la actualidad sólo se adivinan algunos de sus trazos, como hemos podido comprobar.

20 PAREDES, «De la Sociedad Excursionista Extremeña...», citado.

21 Gratiniano Nieto Gallo, Las primeras copias de pinturas rupestres esquemáticas en España, Peña Escrita y La Batanera, Fuencaliente 1783. Nuevamente copiadas por Alfonso Caballero en 1983, Ciudad Real, Museo, 1984, 60 págs. y 36 figs. en láminas. G. Nieto recoge las 


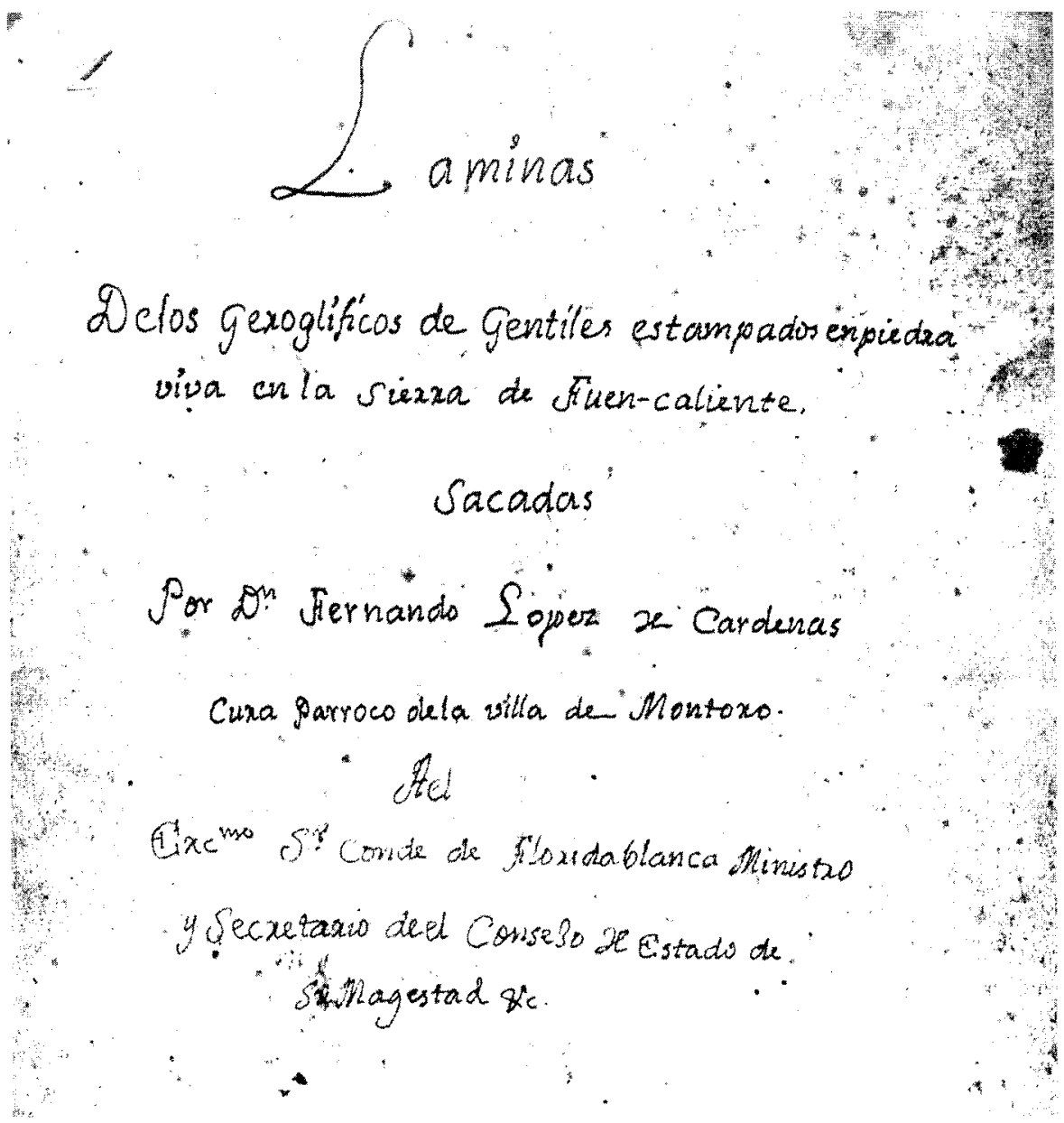

Portadas de las láminas de la "Disertación» de Fernando José López de Cárdenas, el "Cura de Montoro", con las pinturas de Peña Escrita y La Batanera

(Fuencaliente) (1783).

diversas referencias que se hicieron a la Disertación durante el siglo XIX en el Semanario Pintoresco Español $(1844,1846)$, en el Diccionario de Madoz (1847), etc., y especialmente en el pionero libro de M. de Góngora al que se hará referencia más adelante. Al descubrimiento del Cura de Montoro ya dedicó un artículo Henri BrEUIL, «Les peintures rupestres schématiques d’Espagne: les anciennes découvertes. I, La Piedra Escrita y La Batanera à Fuencaliente (Ciudad Real). II, La Cueva de los Letreros a Vélez Blanco (Almería), Butlleti de l'Associació Catalana d'Antropologia, Etnologia $i$ Prehistòria, II, 1924, págs. 43-66, 18 láminas. También del mismo G. NIETO, «Don Fernando José López de Cárdenas, descubridor del arte rupestre esquemático (1783)», Zephyrus, XXXVII-XXXVIII, 1984-1985 (= Homenaje al Prof. Jordá), págs. 211-216, 3 figuras. 
Perplejo ante su hallazgo y conforme con lo que era la formación humanística de su tiempo, el Cura de Montoro atribuyó las pinturas a egipcios, fenicios y cartagineses. De este modo, al comienzo de uno de sus textos, pondera con ingenuidad las obras de arte encontradas:

\begin{abstract}
“Pero en este siglo de ilustración para nuestra España se hace más recomendable este terreno, no sólo para ella: si no es para todo el orbe erudito por sus piedras escritas, y cuebas piramidales en materia viva de pedernal, en que se hallan figurados con tinta de rúbrica bituminosa símbolos, geroglíficos y figuras que no se hallan en los Alphabetos conocidos hasta ahora. Es tan rara esta memoria de la antigüedad gentilicia, que creo, no tienen exemplar en todo el mundo antiguo, ni se hallará otra tal en sus fastos y memorias" 22 .
\end{abstract}

Habría que añadir aquí una referencia a las más antiguas menciones de los llamados petroglifos galaicos, tema en él que suscribe todavía no ha investigado. Por ello nos limitaremos a señalar que algunos datos se contienen en el Viaje a Galicia de fray Martín Sarmiento (1745), que hasta más de cien años después no empezaron a llamar la atención de ciertos eruditos, como J. Villaamil y Castro en su obra Antigüedades prehistóricas y célticas de Galicia (1873).

\title{
2. EL PASO A LA MODERNIDAD
}

Para marcar la trascedental transición de la época de los antecedentes a la del estudio e interpretación correcta del arte prehistórico, debemos referirnos ahora al arte mueble paleolítico como preludio y a la espera de que fuera admitido el arte parietal del mismo período. Para ello tenemos que volver a Francia, e ir también a Suiza, para recordar que en la primera mitad del siglo XIX se recogieron dos huesos grabados que, en su momento, se atribuyeron al tiempo de los celtas.

Uno de ellos es un bastón perforado procedente del lugar de Veyrier (al pie del Mont Salève, Suiza), en asta de reno, que tiene grabado lo que se creyó un gamo y en realidad es un reno. El objeto fue encontrado en 1838 y ahora se conserva en el Museo de Ginebra ${ }^{23}$. El otro es un hueso de reno de la cueva de Chaffaud (Savigné, Vienne), hallado por André Brouillet en sus excavaciones de este yacimiento (entre 1834 y 1845).

22 NIETO, Las primeras copias de pinturas rupestres..., citado, pág. 17.

23 A. FABRE, "Station de l'homme de l'Âge de la Pierre à Veyrier, près de Genève», Matériaux pour l'histoire naturelle ef primitive de l'homme, IV, 1868, pág. 91. 
Lleva la representación de un cérvido - ciervo o reno - visto de perfil. El año 1853 la pieza pasó al parisino Musée de Cluny por consejo del prehistoriador danés J. J. Worsae (1821-1885), y ya allí, fue atribuido al Magdaleniense por R. Fauvelle en $1885^{24}$.

En 1861, Edouard Lartet (1801-1871) ${ }^{25}$ encontró un trozo de candil de ciervo con el grabado de una cabeza de oso en la cueva inferior de Massat (Ariège) y sintió una gran perplejidad ante la segura presencia de un objeto artístico en un nivel de los hombres del Paleolítico superior, a los que entonces se atribuía un estadio de civilización muy primitivo, calificado de «antediluviano». Lartet conocía el hueso de Chaffaud y estimó que su propio hallazgo confirmaba el carácter paleolítico de aquél. A partir de este momento, aunque algunos escépticos se negaban a admitir la existencia de un arte paleolítico, argumentando que aquellas piezas procedían de niveles revueltos, la verdad se fue abriendo camino. En este aspecto fue determinante el hallazgo, en 1864, de una representación de mamut grabada sobre un fragmento de marfil de este animal en el yacimiento de La Madeleine (Tursac, Dordoña), en presencia del propio Lartet que estaba acompañado por el especialista en proboscideos Hugh Falconer (1808$1865)^{26}$. Enseguida los hallazgos se multiplicaron y además de los citados fueron obra de E. Massenat, el Marqués de Vibraye, Ph. Lalande y otros.

En 1875 apareció la obra de Edouard Lartet y Henry Christy (18101865) titulada Reliquiae aquitanicae, verdadero corpus del arte mueble entonces conocido ${ }^{27}$. El arte paleolítico sobre objetos dejaba de ser una cuestión controvertida y pasaba a convertirse en un componente notable de las civilizaciones superopaleolíticas.

24 Worsae era un cercano colaborador de Chr.-J. Thomsen (1788-1865), el inventor del «sistema de las tres edades", que él mismo amplió. Fue una de las personalidades más notables de la naciente Prehistoria, ciencia que difundió en la Universidad de Copenhague y desde la dirección del Museo de Antigüedades Escandinavas. J.J. WORSAE, "Communication», Congrès International d'Anthropologie et d'Archéologie préhistoriques, 4. e sesión, Copenhague, 1869, págs. 127-134. R. FAuvELLE, «Étude sur une gravure magdalénienne du Musée de Cluny», L'Homme, II, 1885, pág. 682.

25 Lartet renunció a la magistratura para dedicarse a la Paleontología y a la Prehistoria. Su excavación de la pequeña cueva de Aurignac (Alto Garona), le sirvió para establecer «la antigüedad geológica del hombre». Propuso una clasificación del Paleolítico basada en las especies animales características de cada período. P. FISCHER, «Note sur les travaux scientifiques d'Edouard Lartet», Bull. de la Soc. Géologique de France, 1871-18t2; Salomon REINACH, Alluvions et cavernes, Paris, 1889, pág. 16.

26 E. LARTET y H. CHRISTY, «Sur des figures d'animaux gravées ou sculptées et autres produits d'art et d'industrie rapportables aux temps primodiaux de la période humaine", Revue Archéologique, IX, 1864, págs. 233-267.

27 Edouard LARTET y Henry CHRISTY, Reliquiae aquitanicae, being contributions to the archeology and paleontology of Perigord, Londres, Ballière, 1865-1875. 
En España, cierra la etapa de los «antecedentes» y abre la de la moderna investigación un libro que significa el cambio de coyuntura que da paso a la modernidad científica: Nos referimos al volumen de Manuel de Góngora y Martínez, Antigüedades prehistóricas de Andalucía, publicado en $1868{ }^{28}$. Dicha obra es una de las primeras aportaciones españolas a la nueva ciencia de la Prehistoria. Al propio tiempo es muy «moderna», en el sentido que su autor está al corriente y maneja muy bien los datos que en su tiempo se poseían. Respecto al tema que aquí nos ocupa, Góngora aporta su propio descubrimiento de las pinturas esquemáticas de la Cueva de los Letreros (Vélez Blanco, Almería) y recuerda y sitúa en su lugar cronológico las halladas por López de Cárdenas, el Cura de Montoro, en Fuencaliente, a las que ya se ha hecho referencia ${ }^{29}$.

Aquellos años que discurren entre 1860 y 1875 constituyen el punto de partida de las modernas investigaciones del arte prehistórico. Precisamente en la segunda de dichas fechas, M. Sanz de Sautuola visitó por primera vez la cueva de Altamira, abriendo muy pronto nuevas perspectivas al arte prehistórico al incorporarle su componente parietal, no sin antes pasar por unos hechos muy lamentables.

\section{MARCELINO SANZ DE SAUTUOLA Y ALTAMIRA}

El santanderino Marcelino Sanz de Sautuola (1831-1888), hijo de una familia pudiente, recibió una esmerada educación que le inclinó al cultivo de las ciencias naturales y de la erudición ${ }^{30}$. Pero su nombre quedaría limitado a los

28 Manuel de Góngora y Martinez, Antigüedades prehistóricas de Andalucía, Madrid, Moro, 1868, 158 págs., 150 figs. y 1 mapa. Muy oportunamente se publicó una edición facsímil de este valioso libro, con estudio preliminar de Mauricio Pastor Muñoz y Juan Antonio Pachón Romero (Granada, Universidad, 1991). M. de Góngora (+ 1864) fue profesor y decano de la Facultad de Filosofía y Letras de la Universidad de Granada. Además del libro aludido, escribió Monumentos del antiguo reino de Granada (1868), El concilio de liberis (1870) y varios manuales de Historia, siendo un asiduo colaborador de la revista Museo Español de Antigüedades.

29 Góngora y Martínez, Antigüedades prehistóricas de Andalucia, citado, págs. 64-75, figs. 70-86.

30 Para la biografía del polígrafo montañés es básico: Benito MADARIAGA DE LA CAMPA, Marcelino Sanz de Sautuola, escritos y documentos, Santander, Inst. Cult. de Cantabria, 1976, 348 págs., con una apéndice de Modesto SANEMETERIO COBO, "Apuntes bibliográficos sobre el descubrimiento de la cueva de Altamira (Santillana del Mar, Santander), 1864-1906", págs. 289-343. El cuerpo de la obra contiene la partida de bautismo, árbol genealógico, papeles administrativos, noticias varias y correspondencia, págs. 205-288. Reproduce, además, el facsímil de Breves apuntes..., págs. 6996, y los de dos manuscritos de Sautuola, uno sobre la aclimatación del eucaliptus en Santander (1866), págs. 55-64, y otro titulado «Breves apuntes sobre el Puente de San Miguel y sobre las Juntas de los nueve valles de Asturias de Santillana» (1881), págs. 107-120. 


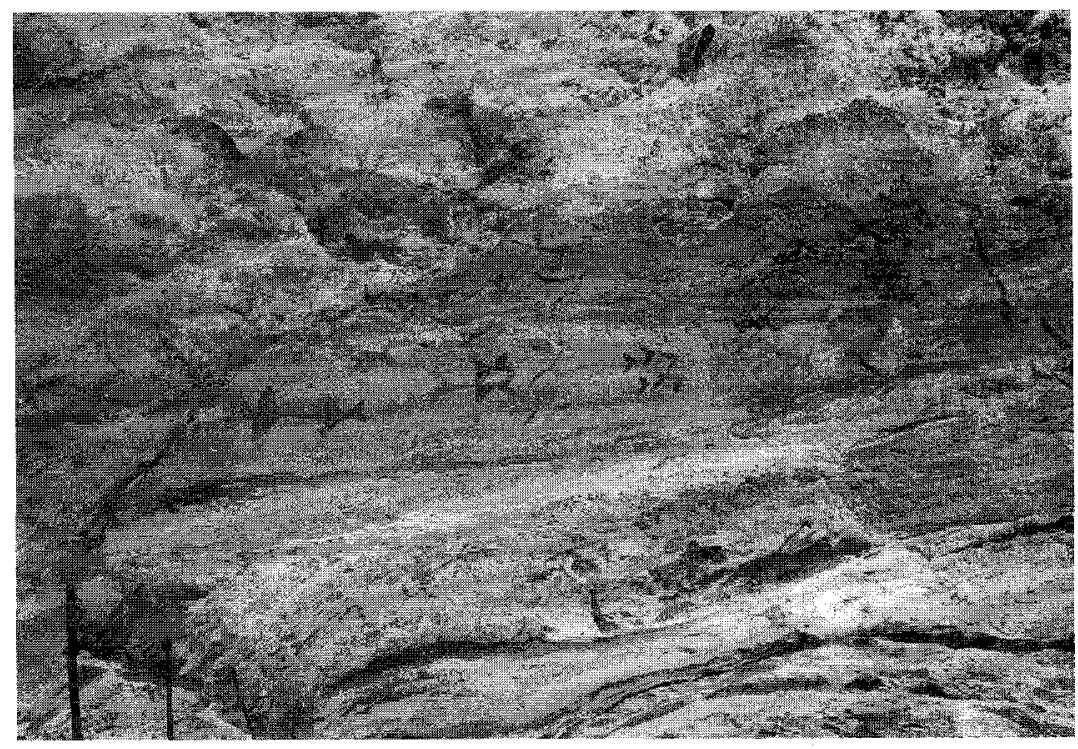

ำ

d)

:

0

농

.

ष

$5 \%$

के

क

ن

옹

N

눈

$\circ$ क

월

등.

응

ब)

(4)

잉ㅇํㅇ

嘀

\&

范

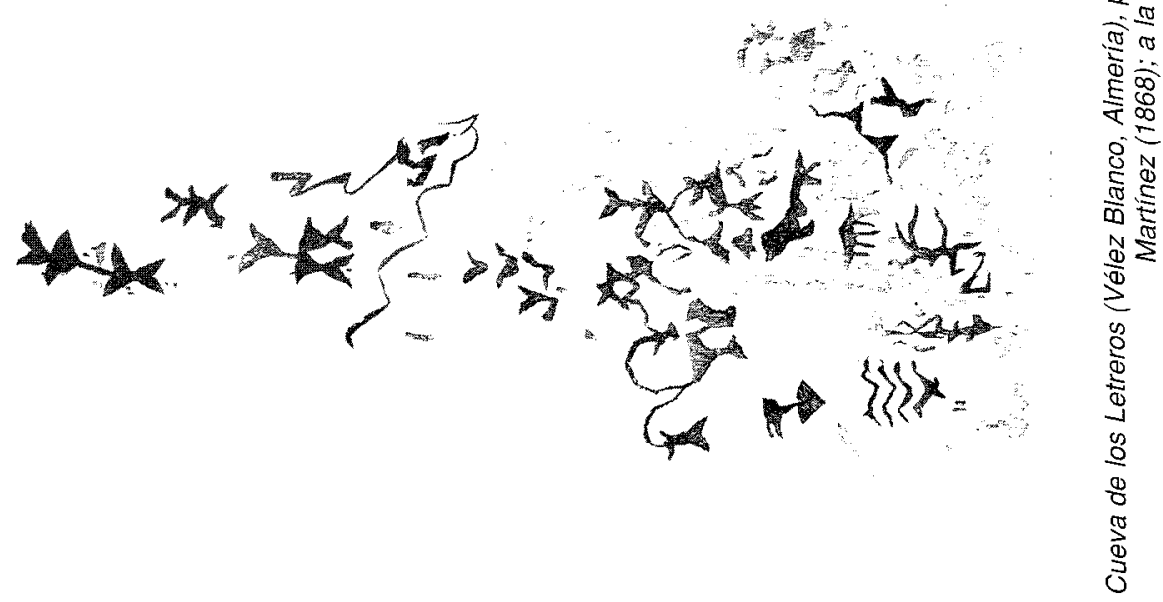

$\frac{\pi}{\pi}$

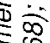

$\infty$

8

要宅

D

$>$

o

()

क

8

वे 
anales de la historia local y a la merecida fama de haber sido el introductor del eucaliptus en el norte de España, de no haberle estado reservado el descubrimiento y la más bella evidencia del arte parietal paleolítico.

En 1875, Sautuola inició unas prospecciones en una cueva situada en un prado llamado Altamira, del pueblo de Vispieres (municipio de Santillana del Mar), que había encontrado un cazador hacía poco tiempo. Ya entonces vislumbró algunas de las figuras de color negro de la galería más interna de la caverna, pero no les dio importancia. Con motivo de sus trabajos de excavación entró en relación con el geólogo Juan Vilanova y Piera (1821-1893) ${ }^{31}$, uno de los pioneros de la ciencia prehistórica en nuestro país. Tres años más tarde, Sautuola aumentó sus conocimientos de Prehistoria al visitar las colecciones que se exhibían en la Exposición Universal de París de 1878. Esto le decidió a reemprender las excavaciones de Altamira, lo que hizo en el verano de 1879. Según las explicaciones orales dadas por él mismo, fue su hija María quien se dio cuenta de la existencia de figuras pintadas en el bajo techo de una sala cercana a la entrada. Su perspicacia puso enseguida en relación los dibujos de color negro vistos en 1875 con las figuras "polícromas» ahora descubiertas. La perplejidad que éstas provocaron en Sautuola no empañó su visión clara y certera de la importancia y exacta calificación de su hallazgo que enseguida comunicó a Vilanova y Piera. Muy poco después, en 1880, publicó su opúsculo titulado Breves apuntes sobre algunos objetos prehistóricos de la provincia de Santander ${ }^{32}$. En este folleto de 27 páginas, que conserva en la actuailidad un gran valor científico, dio a conocer sus descubrimientos. He aquí unas frases que ejemplifican la objetividad de Sautuola:

«Respecto a las pinturas que se han encontrado, es indudable que las de la primera galería acusan una perfección notable comparadas con las demás, pero a pesar de todo, su examen detenido inclina al ánimo a suponerlas contemporáneas unas de otras. Más difícil será resolver si todas ellas corresponden a la remotísima época en que los habitantes de esta cueva formaron el gran depósito que en ella se encierra; pero por más que esto parezca poco probable tomando en cuenta su buen estado de conservación, déspués de tantos años, conviene hacer notar que entre los huesos y cáscaras se han

31 Vilanova y Piera, geólogo, paleontólogo y prehistoriador valenciano, catedrático primero en Valencia y luego en Madrid, vinculado a la Institución Libre de la Enseñanza. Debe ser considerado como el introductor de la Prehistoria científica en España. Escribió manuales y obras de investigación. Juan VILANOVA Y PIERA, Origen, naturaleza y antigüedad del Hombre, Madrid, 1872. Francisco QuiRoga Rodriguez, «Necrología de D. Juan Vilanova y Piera», Anales de la Sociedad Española de Historia Natural, Actas XXII, 1893, págs. 132-137. Mariano AyarzagüEnA Sanz, «Juan Vilanova y Piera, Padre de la Prehistoria española", Revista de Arqueología, n 108, IV, 1990, págs. 40-43.

32 Marcelino S. DE SAUTUOLA, Breves apuntes sobre algunos objetos prehistóricos de la provincia de Santander, Santander, T. Martínez, 1880 (reeditado en facsímil en varias ocasiones). 


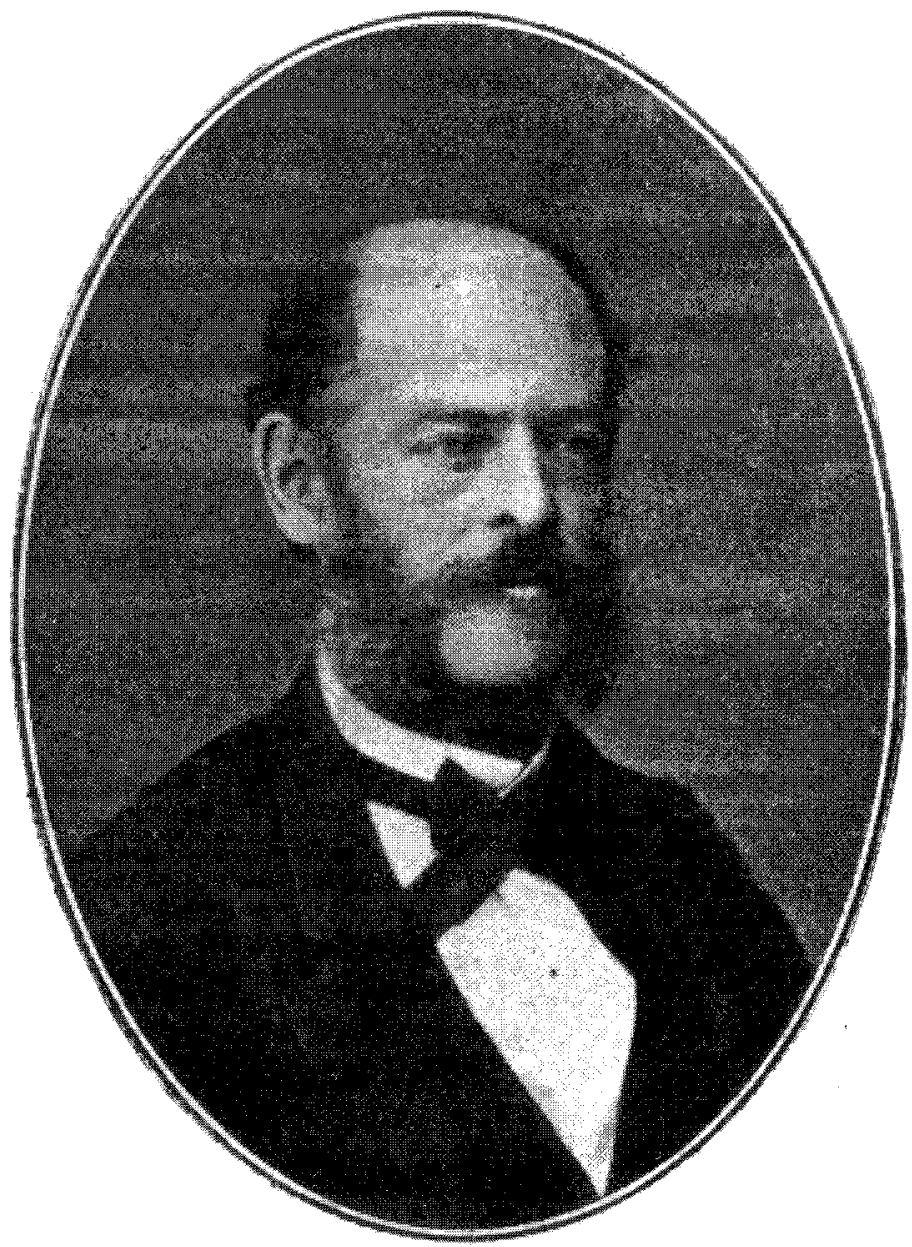

Don Marcelino Sanz de Sautuola (183:-1888), descubridor de las pinturas de Altamira

hallado pedazos de ocres rojos, que, sin gran dificultad pudieran haber servido para estas pinturas..." ${ }^{33}$.

La noticia del descubrimiento fue recibida con escepticismo y recelo por los círculos científicos, franceses y españoles, que, enseguida, con un apriorismo absurdo, consideraron falsas las obras de arte altamirenses.

33 Sautuola, Breves apuntes..., citado, págs. 20-21. 
Portavoces de esta opinión en Francia fueron Gabriel de Mortillet (18211898) ${ }^{34}$ y Émile Cartailhac (1845-1921) ${ }^{35}$, que, desde sus puestos eminentes en la Prehistoria francesa acallaron las dudas que podían sentir otros investigadores. El primero, en su libro Le préhistorique, cita Altamira como yacimiento paleolítico pero ni siquiera menciona sus obras de arte. Por su parte, el segundo no la cita en su obra sobre la Prehistoria de la Península lbérica. Cartailhac se apoyaba tan sólo en un informe del ingeniero y paleontólogo Edouard Harlé (1850-1922), el único que, aparte de algunos españoles, conocía la cueva de visu, si bien se dejó influenciar por una habladuría según la cual en la realización de las pinturas intervino un pintor sordomudo recogido por caridad en casa de Sautuola ${ }^{36}$.

El principal valedor de Sautuola en los foros internacionales fue su amigo Vilanova y Piera. Tras un viaje a Santander para ver la cueva y dar unas conferencias, Vilanova asistió al $\mid X^{*}$ Congrès International d'Anthropologie et d'Archéologie Préhistoriques (Lisboa, 19-29 de septiembre de 1880), durante el cual repartió ejemplares del fascículo de Sautuola y, en nombre de la corporación municipal de Santillana, invitó a los participantes a visitar Altamira tras el congreso. Por lo que se sabe, tan sólo H. Henri-Martin (1864-1936), el descubridor y estudioso de la cueva de La Quina (Charente) y luego de los frisos esculpidos solutrenses de Roc de Sers (Charente) en $1907^{37}$, se excusó en una carta muy cortés enviada a Vilanova desde la misma Lisboa el 5 de octubre de 1880. Con

34 Gabriel DE MORTILLET, Le préhistorique, antiquité de lhomme, París, C. Reinwald, 1883, 642 págs. (2. ${ }^{a}$ ed., 1892).

35 Cartailhac fue profesor de Antropología y Arqueología prehistóricas en Toulouse. En 1869 compró a G. de Mortillet la revista Matériaux..., en la que se publicaron muchos hallazgos de arte mueble (pervivió hasta su tomo XXII, 1888). Fue uno de los fundadores de L'Anthropologie (1890). De su enorme bibliografía cabe destacar. Émile CARTAlLHAC, Les âges préhistoriques de l'Espagne et du Portugal, París, Reinwald, 1886; La France préhistorique d'après les sepultures et les monuments, París, Alcan, 1889; Monuments primitifs des lles Baléares, Toulouse, Privat, 1892 (existe edición facsímil, con texto traducido al castellano e introducción de G. RossellóBordoy, Palma de Mallorca, Olañeta, 1991); "Les stations de Bruniquel sur les bords de l'Aveyron", L'Anthropologie, XIV, 1903, págs. 129-150 y 295-315, 133 figs. (con muchas piezas de arte mueble). Artículo biobibliogrático por Marcellin Boule, en L'Anthropologie, XXXI, 1921, págs. 587-608. El Abate Breuil dijo de Cartailhac: Acaso más que las páginas que escribio, sus obras son sus discipulos.

36 E. HARLÉ, "La grotte d'Altamira près Santander (Espagne)". Matériaux pour l'histoire primitive et naturelle de l'homme, XII, 1881, págs. 275-284. Rectificación tardía de Harlé: Jesús Carballo, Descubrimiento de la cueva y pinturas de Altamira por D. Marcelino $S$. de Sautuola, Santander, Patronato de las Cuevas, 1950, págs. XLVII-L (obra en la que también se publicó un facsímil del opúsculo de Sautuola).

${ }_{37}$ H. Henri-Martín, La frise sculptée et l'atelier solutréen du Roc (Charente), Archives de l'IPH n 5, 1928, 87 págs. y 4 láms.; Id., "Les sculptures du Roc", Préhistoire, 1, 1932, págs. 1-8, 2 láminas. Raymond LANTIER, "Las excavaciones del santuario solutrense de Roc de Sers", Archivo Español de Arqueología, XXV, 1952, págs. 321-335. 


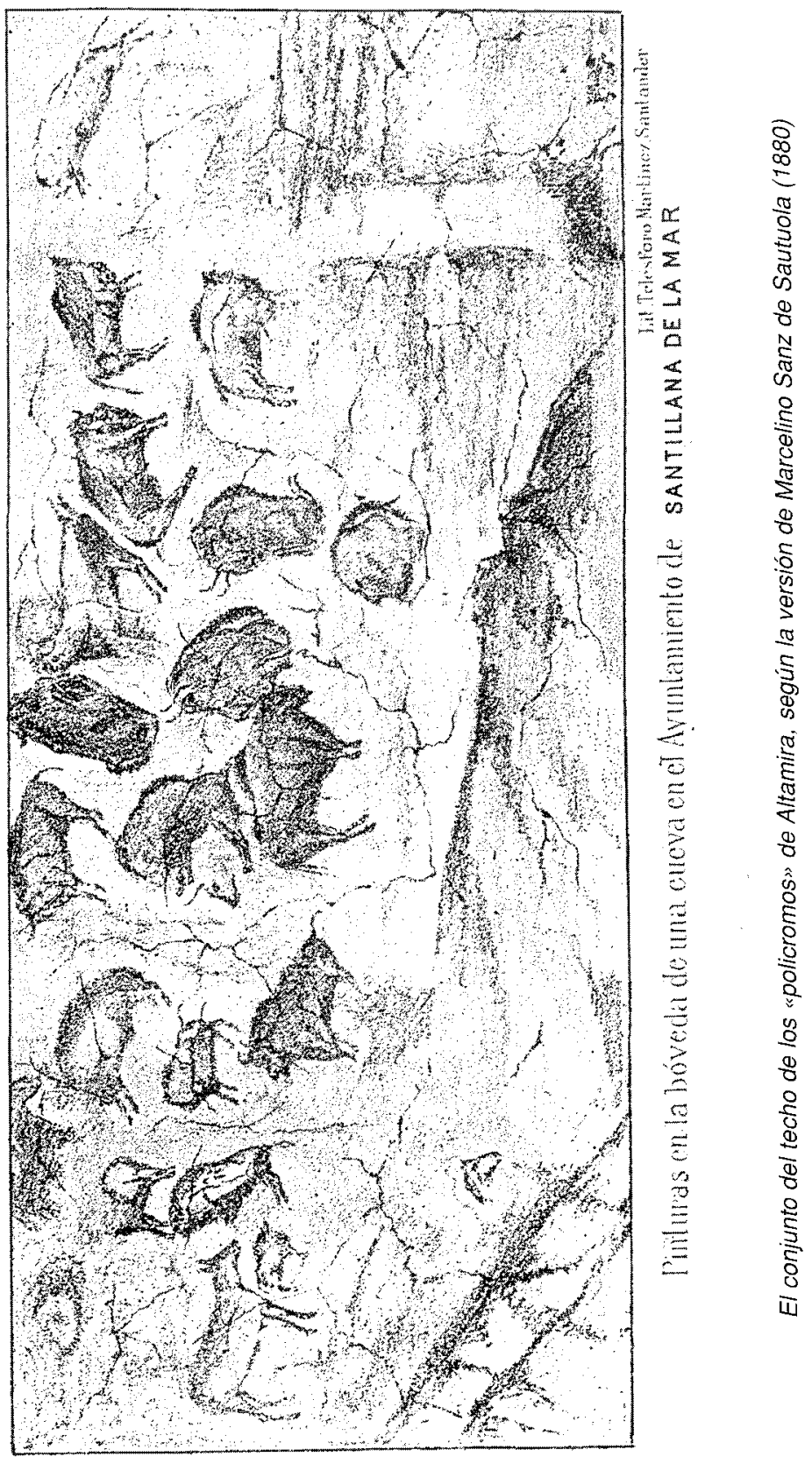


buen acierto hace en ella algunas consideraciones sobre la fauna representada y aconseja la busca de paralelos en el arte mueble, admitiendo tácitamente la autenticidad de las pinturas ${ }^{38}$.

Unos años después, era el eminente Edouard Piette (1827-1906) ${ }^{39}$, gran conocedor del arte mueble, quien reconocía el valor y la importancia de la cueva de Santillana, proponiendo por primera vez - y acertadamente - su atribución cultural. En una misiva a Cartailhac, de fecha 18 de febrero de 1887, que éste no atendió, le decía:

«Don Marcellino de Sautuola m'a envoyé sa brochure sur les objets préhistoriques de la Province de Santander, et notamment sur les peintures de la grotte de Santillana del Mar... Je ne doute pus que ces peintures ne soient de l'époque Magdalénienne» 40.

Pero toda esta historia se desarrolla sin acritud, como se puede comprobar en una muy amable carta que Cartailhac escribe a Sautuola el 5 de diciembre de 1880. En ella califica su descubrimiento como el más importante que se ha hecho en España, le habla de los bóvidos representados y le da consejos acerca de sus investigaciones, pero no se pronuncia sobre la autenticidad o la falsedad de las obras de arte altamirenses ${ }^{41}$.

En España, las opiniones de la ciencia que podríamos llamar «oficial» eran eco, en parte, de las que corrían en Francia y se expusieron en las sesiones de la Real Sociedad Española de Historia Natural ${ }^{42}$. Los naturalistas Ignacio Bolivar, Eugenio Lemus, F. Quiroga y E. Torres Campos, el antropólogo Manuel Antón e incluso el estudioso de las cavernas españolas

38 Fue publicada en el diario El Eco de la Montaña de 31 de octubre de 1880, traducida del francés. Texto exhumado por MAdaRIAGA DE LA CAMPA, Marcelino Sanz de Sautuola..., citado, págs. 47-49.

39 Magistrado y prehistoriador que realizó numerosas excavaciones en yacimientos de los Pirineos y las Landas. Reunió una importante colección que en 1904-1905 donó al Musée des Antiquités Nationales (Saint-Germain-en-Laye), donde se conserva en la sala que lleva su nombre. La publicó Marthe CHOLLOT, Collection Piette, art mobilier préhistorique, París, 1964. Piette creó el epónimo Aziliense (de Mas d'Azil) para la etapa final del Paleolítico superior. Henri BREUIL, "L'evolution de l'art quaternaire et les travaux d'Edouard Piette», Revue Archéologique, XII, 1909, págs. 378-411, 13 figuras. Necrología por M. Boule, en L'Anthropologie, XVII, 1906, págs. 214-224 (con su bibliografía). Henri DelPORTE, Pjette, pionnier de la Préhistoire, París, Picard, 1987.

40 L. Capitán, H. Breull y D. Peyrony, La caverna de Font-de-Gaume aux Eyzies (Dordogne), Mónaco, Impr. Vve. A. Chêne, 1910, 271 págs., 244 figs. y 65 láminas. El texto en la nota 1 de la pág. VII, con el siguiente comentario: C'est donc a Piette que revient I honneur d'avoir le premier en France compris la portée de la découverte espagnole.

41 Publicada en El Eco de la Montaña, de 30 de diciembre de 1880, traducida del francés. También esta misiva fue señalada por MADARIAGA DE LA CAMPA, Marcelino Sanz de Sautuola..., citado, págs. 49-51.

42 Las actas de las sesiones de la Real Sociedad Española de Historia Natural, recogidas en Madariaga de LA CAMPa, Marcelino Sanz de Sautuola..., citado, págs. 173-203. 


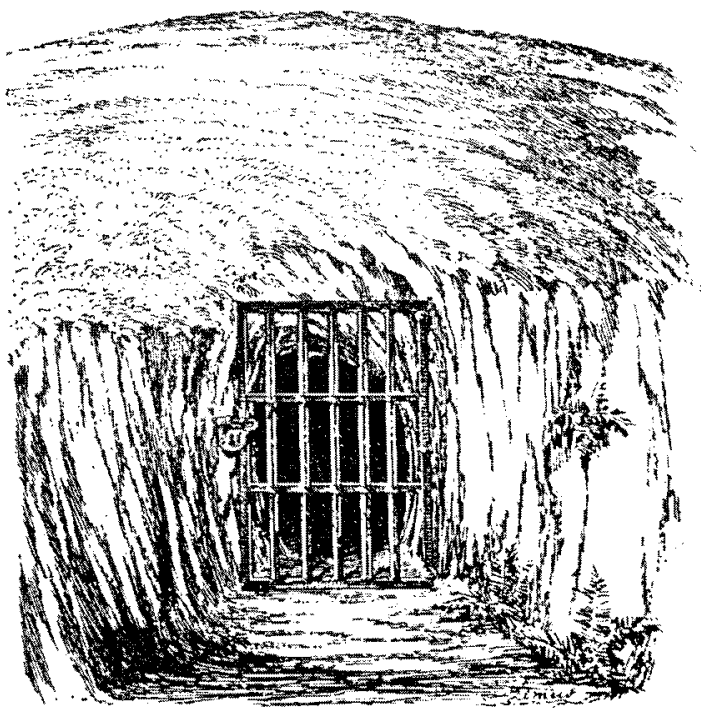

Puerta de cierre de la cueva de Altamira, hecha instalar por M. Sanz de Sautuola a finales de 1879 (dibujo de E. Lemus, hacia 1884)

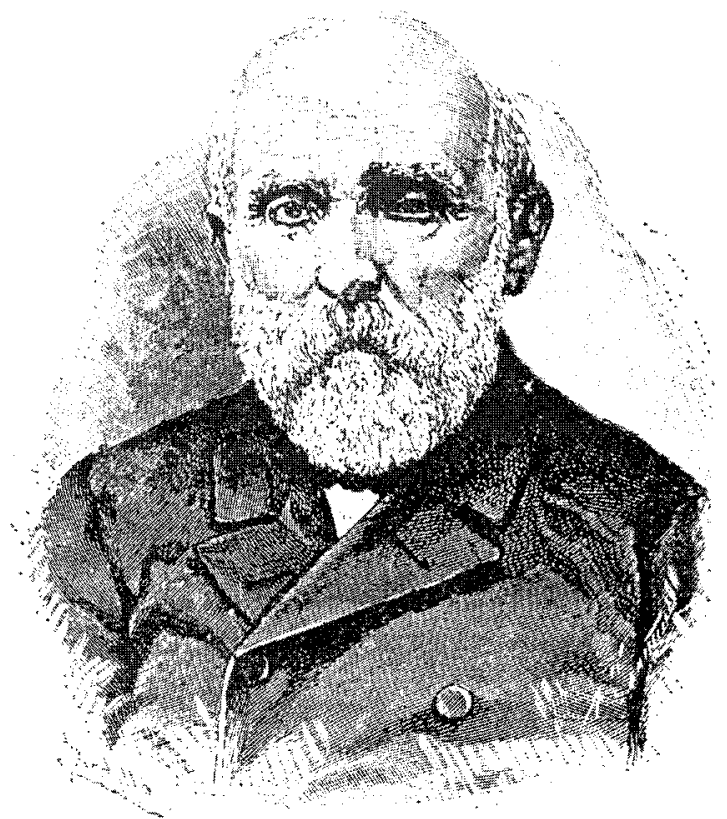

El geólogo, prehistoriador y académico Don Juan Vilanova y Piera (1821-1893) 
J. Puig y Larraz, negaron la autenticidad de las pinturas, a veces con argumentos poco científicos. En su ámbito local, Sautuola mantuvo una polémica con el historiador Ángel de los Ríos, que negaba cualquier logro de la Prehistoria y atribuía las pinturas a los modernos vaqueros transhumantes ${ }^{43}$. Pero también contaba con el cálido apoyo de buenos amigos como Eduardo Pérez del Molino, Eduardo de la Pedraja, Augusto González Linares y J. Jiménez de la Espada, que se interesaban por los estudios prehistóricos ${ }^{44}$. En Madrid y ante la ciencia foránea, el principal valedor era Vilanova y Piera que, después de aquel congreso de Lisboa (1880), habló inútilmente de Altamira en los de Argel (1881), Berlín (1882), La Rochelle (1882) y Nancy (1886). Vilanova, además, en sus análisis, llegó a la conclusión que las pinturas de la cueva de Santillana eran del Magdaleniense. Así, en 1890, en su obra general en colaboración con Juan de Dios de la Rada y Delgado (1827-1901), en la que las partes de ambos autores están bien individualizadas, dedica siete páginas a Altamira, sumando nuevas noticias y argumentos en favor de su autenticidad, en especial al poner en relación las pinturas con el arte mueble conocido en Francia $44 \mathrm{bis}$.

Desgraciadamente el sabio valenciano murió en 1893, mientras que el santanderino Sautuola había fallecido en 1888. Por tanto, ambos desaparecieron sin ver reconocido lo que había sido objeto de sus afanes: Altamira y su arte parietal. El insigne Menéndez y Pelayo, que siempre prestó atención a los avances de la ciencia prehistórica, escribió respecto al descubridor lo que podría ser un bello epitafio:

«La verdadera revelación del arte primitivo se debe a un español modestísimo, el caballero montañés D. Marcelino de Sautuola, persona muy culta y aficionada a los buenos estudios, pero que, seguramente, no pudo adivinar nunca que su nombre llegaría a hacerse inmortal en los anales de la Prehistoria» ${ }^{45}$.

La reivindicación no tardaría en llegar y la cueva y sus pinturas fueron pronto elevados a la categoría de gran monumento. Sería el eminente Joseph Déchelette (1862-1914) quien, en 1908, le dio la denominación de "Capilla Sixtina del arte cuaternario" ${ }^{46}$.

\footnotetext{
${ }^{43}$ Los escritos se cruzaron en las páginas del diario El Eco de la Montaña entre los meses de septiembre de 1880 y enero de 1881 y sus textos fueron transcritos por MADARIAGA DE LA CAMPA, Marcelino Sanz de Sautuola..., citado, 123-172.

44. Madariaga de la Campa, Marcelino Sanz de Sautuola..., citado, pássim.

44bis Juan ViLANOVA Y PIEPA y Juan DE DIOS DE LA RADA y DELGado, Geología y Protohistoria ibéricas, vol. I de Antonio Canduas del Castillo, Historia general de España, Madrid, Progreso Editorial, 1890. El texto sobre Altamira en las págs. 451-458.

45 Menéndez y Pelayo, Historia de los heterodoxos..., citado, pág. 80.

46 J. DÉCHELETTE, Manuel d'Archéologie préhistorique, t. I, París, Picard, 1908, pág. 150.
} 
En efecto, la pérdida de aquellos dos grandes hombres coincide con la puesta en marcha de la rectificación. En 1895, Lombard Dumas percibe una silueta de mamut en la cueva de Chabot (Gard) que pronto estudió L. Chirón ${ }^{47}$, al propio tiempo que Émile Rivière (1835-1922) autentificaba los grabados y pinturas de La Mouthe (Sireuil, Dordoña), encontrados poco antes por unos visitantes ${ }^{48}$. En la misma linea, en 1896, François Daleau (1845-1927), aleccionado por los hallazgos de Rivière, encuentra los grabados zoomorfos de la cueva de Pair-non-Pair (Gironde), que él mismo ya había advertido en $1883^{49}$, mientras que, el mismo año, Félix Regnault (1847-1908) descubría las pinturas de Marsoulas (Alto Garona) ${ }^{50}$. La reivindicación de Altamira estaba preparada.

\section{EL ABATE BREUIL, UNA VIDA DEDICADA AL ARTE PREHISTÓRICO}

Al comenzar el nuevo siglo aparece en este panorama el hombre que a lo largo de sesenta años realizará las mayores aportaciones al conocimiento e interpretación del arte prehistórico. Nos referimos al Abate Henri Breuil (1877-1961), cuyo nombre es inseparable de este tipo de investigaciones en muy diversas regiones del Viejo Mundo. Estudió la carrera sacerdotal en el seminario de Issy-les-Molineaux y aunque tuvo la dignidad de canónigo de las sedes de Soissons y de Beauvais, quiso siempre que se le llamara sencillamente abbé. Se licenció en ciencias naturales en la Sorbona en 1904, cuando ya era conocido por sus primeros trabajos. Tras una inicial orientación juvenil a la investigación de la Edad del Bronce, pasó enseguida al estudio del Paleolítico y muy particularmente de su arte. Sus superiores eclesiásticos le autorizaron en todo momento a dedicarse a

47 L. CHIRON y CL. GaILLARD, «L'industrie et la faune des grottes Chabot et du Figuier sur les bords de l'Ardèche", L'Homme préhistorique, 5, 1911, págs. 1-19. Jean ComBIER en L'Art des cavernes. Atlas des grottes ornées paléolithiques trançaises, Paris, Impr. Nationale, 1984, págs. 317-322.

48 E. RIVIĖRE, «La grotte de La Mouthe (Dordogne)», Bulletin de la Société archéologique du Périgord, 4, 1897, págs. 302-329, 484-490 y 497-503; Id., "La grotte de La Mouthe (Dordogne), Bull. et Mém. de la Société d'Anthropologie de París, 5, 1901, págs. 509-517, y otros trabajos de este mismo autor. N. Aujoulat y J. M. Geneste, en L'Art des cavernes..., citado, págs. 144-147.

49 François DALEAU, «Gravures préhistoriques de la grotte de Pair-non-Pair, commune de Marcamps (Gironde)", 31 e Congrès de l'Association Française pour l'Avancement des Sciences, Montauban, 1902, t. 2, págs. 786-789. Puesta en valor de los hallazgos de Daleau: A. CHEYNIER, La caverne de Pair-non-Pair, Gironde: Fouilles de François Daleau, Burdeos, 1963, que contiene H. BREutL, M. E. Boyle y L. DolzE, «Relevés des gravures des parois de la caverna de Pair-non-Pair», págs. 186-216. Alain Roussot, La découverte des gravures de Pair-non-Pair d'après les notes de François Daleau, Limoges, 1973. A. Roussot, en L'Art des cavernes..., citado, págs. 256-262.

50 F. Regnault, «Peintures et gravures dans la grotte de Marsoulas», Bulletin Archéologique, 1903, págs. 209-211. Pero, en dicha fecha el arte de esta cueva ya había sido objeto de un estudio sistemático de E. Cartailhac y H. Breuil publicado en L'Anthropologie dos años después. 
la investigación, lo que le permitió vivir una existencia repleta de actividad y de cuyo devenir nos hemos ocupado ${ }^{51}$.

En 1897, Breuil empezó a trabajar con E. Piette que estaba excavando la Grotte du Pape, en Brassempouy (Landas). El joven seminarista tenía veinte años y setenta el gran estudioso del arte mueble. Piette había reunido en su casa de Rumigny (Ardenas) una notable colección que empezó a dibujar Breuil, quien, además, participó en sus trabajos de campo. Fue una colaboración que continuó hasta la muerte de Piette e incluso prosiguió después de su fallecimiento ${ }^{52}$. Aquellas labores dieron al joven un buen conocimiento del arte mueble e hicieron que se planteara la problemática del arte parietal. En 1900 visitó la cueva de La Mouthe y contempló por primera vez pinturas y grabados en los muros de una caverna. En aquellos años, también colaboraba con Louis Capitan (1854-1929) y con Denis Peyrony (1869-1954). Con ellos, en el verano de 1901, Breuil descubre las notables cuevas de Les Combarelles y Font de Gaume (ambas en Les Eyzies, Dordoña) ${ }^{53}$.

Cuando, en agosto de 1902, se celebró en Montauban un congreso de la Association Française pour l'Avancement des Sciences, con muy amplia participación de prehistoriadores, se imponía el que se tratase del problema del arte parietal. Una parte de los congresistas se trasladaron a Les Eyzies para ver sus tres cuevas con arte. Aquél fue el «camino de Damasco» de Cartailhac. Era el 14 de agosto de 1902.

Cartailhac escribió entonces su noble retractación sobre el arte de Altamira y la figura de Sautuola ${ }^{54}$. Enseguida invitó a Breuil a que le acompa-

51 Ripoll. Perelló, El Abate Henri Breuil (1877-1961), Madrid, UNED, 1994, 376 págs., con figs. y XLVIII láms. (bibliografia de H. Breuil: 834 títulos), con un «Prefacio» del Abate escrito en 1960, «Mis trabajos sobre el arte paleolítico en España (1902-1954)», págs. 9-23. Dimos una primera y corta versión de dicho libro en «Vida y obra del Abate Henri Breuil, padre de la Prehistoria», introducción a (E. RIPOLL PERELLó, ed.), Miscelánea en homenaje al Abate Henri Breuil (1877-1961), Barcelona, IPA, 1964-1965, 2 vols., págs. $1-70$ del tomo I.

52 Breuil, con $\mathrm{H}$. Fischer, colaboró en la edición de la obra póstuma de Edouard PIETTE, L'Art pendant l'Áge du Renne. Album de cent planches dessinées par J. Pllloy, París, Masson, 1907. RIPOLL, El Abate Henri Breuil..., citado, págs. 42-45.

53 L. Capitan, H. Breull y D. Peyrony, La caverna de Font-de-Gaume aux Eyzies (Dordogne), citado. De los mismos: Les Combarelles aux Eyzies, París, Masson, 1924, X + 192 págs., 128 figs. y 580 láminas. En ambos hay las referencias a trabajos publicados antes de sus fechas de edición. La tardía aparición del segundo se debe a la crisis económica del institut de Paléontologie Humaine en los años que siguieron a la primera guerra mundial. Acerca de L'Anthropologie en su centenario, y los ochenta años del IPH, E. RIPOLLL PERELLó, «L'Anthropologie y el Institut de Paléontologie Humaine", Espacio, Tiempo y Forma, serie I, Prehist. y Arqueol., 9, 1996, págs. 305-319, 3 figuras.

54 E. CARTAILHAC, "Les cavernes ornées de dessins. La grotte d'Altamira. Mea culpa d'un sceptique», L'Anthropologie, XIII, 1902, págs. 348-354, 2 figuras. Se le anticipó en la rectificación otro «escéptico»: Marcellin Boule, «Les gravures et peintures sur les parois des cavernes», L'Anthropologie, XII, 1901, págs. 671-677. 


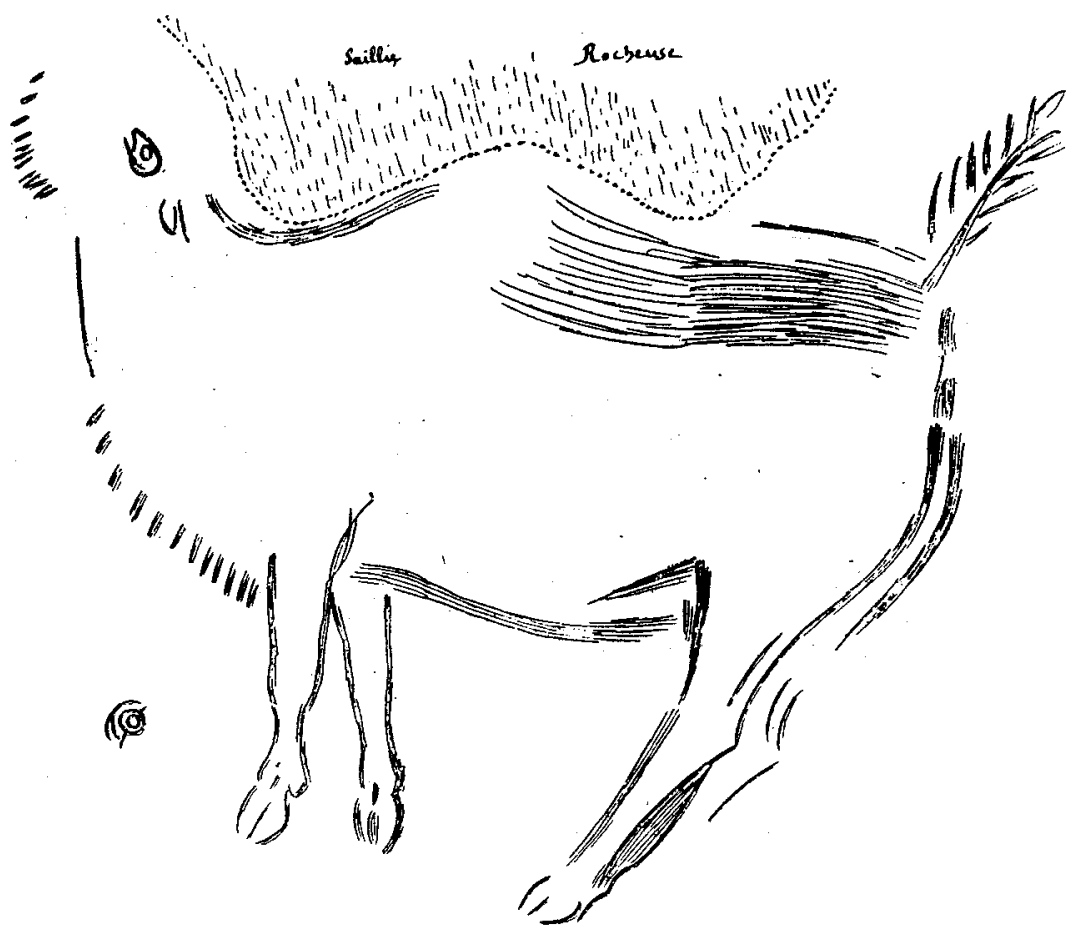

Partes grabadas y aprovechamiento del relieve en uno de los bisontes del plafón de Altamira (según H. Breuil, 1902)

ñara en el estudio de la cueva de Marsoulas, con lo que quería probar sus habilidades técnicas en la copia de grabados y pinturas ${ }^{55}$. Les acompañaron F. Regnault y E. Harlé. Allí mismo, Cartailhac y Breuil decidieron ir a Altamira. En Santander les atendieron Marcelino Menéndez Pelayo, Eduardo Pérez del Molino, J. Millares y los hermanos Lasso de la Vega. Visitaron la cueva y se instalaron en Santillana el día 30 de septiembre de 1902. El abate nos dejó unas breves páginas acerca de las condiciones y la forma en que realizó los calcos. De su texto entresacamos algunos párrafos:

«Era inútil pensar en calcar los grandes frescos del plafón en el estado semilíquido en que la condensación de la humedad reinante mantenía los colores... Tuve que hacer de cada gran figura una copia geométrica a partir

55 E. CARTAILHAC y H. BREUIL, "Les peintures et gravures murales des cavernes pyrénéennes. II, Marsoulas, près Salies-du-Salat (Haute Garonne)", L'Anthropologie, XVI, 1905, págs. 431444, 10 figuras. Aleth Plenier, L'Art des cavernes..., citado, págs. 446-450. 
de un croquis a mano alzada en el que anotaba las dimensiones: éstas eran tomadas por Cartailhac y Nardo entre los puntos que, tumbado sobre un saco de helechos, yo les iba indicando con una caña. Entonces salía de la sala oscura para ir a la claridad de la entrada para trasladar la triangulación obtenida de la figura a la escala de un quinto, volviendo después a mis sacos de helechos. Todo ello estaba iluminado por dos sencillos candelabros en forma de trébedes, cada uno de los cuales llevaba en la parte superior 10 velas de estearina ordinaria (la lámpara de acetileno todavía no estaba en uso)... Nuestra modesta subvención de 500 francos, incluso entonces con un cambio muy favorable, disminuía con rapidez y vela en la cara de Cartailhac el reflejo de las naturales preocupaciones. Felizmente yo había previsto esta circunstancia y, para sosegarle, le entregué los 400 francos que algunas semanas antes me había dado generosamente Edouard Piette para pagarme la copia de un cierto número de dibujos grabados de sus colecciones pirenaicas de la Edad del Reno... En medio de una puesta de sol gloriosa, una de las más extraordinarias que jamás he visto y que abarcaba todo el cielo y la bahía, Cartailhac y yo volvimos a tomar el pequeño tren hacia Bilbao y hacia Francia, cargados con mis preciosas copias. Llevábamos, si puedo decirlo, la "fortuna" de las cuevas con arte destinadas a provocar la admiración,de todo el mundo científico e incluso el culto...." ${ }^{56}$.

De aquel viaje saldrán tres artículos y un gran libro. Los primeros se publicaron pronto: son notas remitidas a las parisinas Académie des Inscriptions et Belles Lettres y la Académie des Sciences, así como un trabajo más amplio en L'Anthropologie ${ }^{57}$. Para el libro se necesitaba un mecenas generoso y éste se encontró en la persona del Príncipe de Mónaco.

Alberto I, príncipe de Mónaco (1848-1922) ${ }^{58}$, se interesaba por el origen de la vida - oceanografía - y por el del hombre - prehistoria -. En este segundo aspecto había patrocinado los estudios y publicaciones de las cuevas de Balzi Rossi, o Grimaldi, cuyos hallazgos fueron el germen del Musée d'Anthropologie Préhistorique de Mónaco, que sigue siendo un importante centro de investigación. Gracias a la intervención de Gustave Saige, secretario y archivero del príncipe, y del arqueólogo e historiador del arte Salomon Reinach (1858-1932), las carpetas con los pasteles de Altamira hechos por el abate Breuil en 1902, pronto estuvieron sobre la mesa de trabajo del soberano monegasco que las examinó entusiasmado. El 11 de noviembre de 1904, el príncipe asumió el mecenazgo de la publicación del gran volumen de

56 Breull, «Prefacio», citado, fragmentos de las págs. 9-13.

57 E. Cartailhac y H. BreuiL, "Les peintures préhistoriques de la grotte d'Altamira à Santillane (Espagne)", C. R. de l'Académie des Inscriptions et Belles Lettres, 1903, págs. 256-265; Id., "Les peintures de la grotte d'Altamira (Espagne)", C. A. de l'Académie des Sciences, t. 136, 1903, págs. 1.534-1.536; Id., "Les peintures et gravures murales des cavernes pyrénéennes. I, Altamira à Santillane (Espagne)", L'Anthropologie, XV, 1904, págs. 625-641, 18 figuras.

58 Raymond DAmIEN, Albert ler, prince souverain de Monaco, París, 1964. 
Altamira ${ }^{59}$, que pronto extendió a un trust para la publicación de otras cuevas con arte, en el que se integraron los franceses É. Cartailhac, H. Breuil, F. Daleau y Denis Peyrony, junto con los españoles Hermilio Alcalde del Río y Juan Cabré Aguiló ${ }^{60}$. Pronto la acción se extendió a lo arqueológico, con la excavación de las cuevas de Castillo, Hornos de la Peña y EI Valle.

Para Altamira hubo unas pocas resistencias, pronto abandonadas ${ }^{61}$. La obra de Cartailhac y Breuil se publicó en 1906, tuvo un gran éxito y se difundió ampliamente. Desde dicho año habían pasado sólo dieciocho desde la muerte de Sautuola, pero en Santander ya estaba trabajando otro gran investigador.

\section{DON HERMILIO ALCALDE DEL RIOO Y SU OBRA}

Mientras Cartailhac y Breuil estaban estudiando Altamira recibieron la visita de Hermilio Alcalde del Río (1866-1947) que tenía que ser el mayor descubridor de cuevas con arte paleolítico de nuestro país ${ }^{62}$. Para reflejar la personalidad y gran labor de este prehistoriador y etnólogo montañés nada mejor que transcribir un texto de su gran amigo el abate Breuil:

"Hermilio Alcalde del Río, un hombre pequeño y delgado que un día nos había hecho una visita a Altamira, inmediatamente después de nuestra partida se lanzó al campo para encontrar otras cuevas pintadas, el 27 de octubre de 1903 descubrió, cerca de Ramales, la cueva pintada de Covalanas, e inició una fructífera colaboración con el Padre Lorenzo Sierra, superior del Colegio de Limpias. El 8 de noviembre de 1903, Alcalde penetró en la grandiosa caverna existente en el monte que domina Puente Viesgo. Esta cueva, llamada del Castillo, estaba llena de pinturas y grabados, y en su entrada se encontraba un rico yacimiento. El 27 de noviembre penetraba en la cueva grabada de Hornos de la Peña. Con estos magníficos descubrimientos publicó en 1906 un importante fascículo ${ }^{63}$. La falta de una lengua común había

59 Émile CARTAILHAC y Henri Breull, La caverne d'Altamira à Santillane, près Santander (Espagne), Mónaco, Imprimerie de Monaco, 1906, VIII + 287 págs., 205 figs. y 38 láminas.

60 RIPOLL, "L'Anthropologie y el Institut de Paléontologie Humaine», citado, pág. 316.

61 E. A. MARTEL, «Réflexion sur Altamira. L'âge des gravures et peintures des cavernes», Congrès Préhistorique de France, lere session, Périgueux, 1905, págs. 112 y siguientes. H. BREUIL, "L'âge des peintures d'Altamira, a propos d'un article recent», La Revue Préhistorique, I, $\mathrm{n}^{\circ} 8$, 1906 , págs. 237-268.

62 Benito Madariaga de la Campa, Hermilio Alcalde del Río, una escuela de Prehistoria en Santander, Santander, 1972, 260 págs., con figuras. E. RIPOLL PERELLó, «Algunas cartas de don Hermilio Alcalde del Río al abate Henri Breuil», (J.A. LAS HERAS, ed.), Homenaje al Dr. Joaquín González Echegaray, Santander, Museo y Centro de Investigación de Altamira, monografías n.? 17, 1993, págs. 199-204, 1 figura.

63 H. Alcalde DEL Río, Las pinturas y grabados de las cavernas prehistóricas de la provincia de Santander, Santander, Blanchard y Arce, 1906 (editado asimismo en la revista Portugalia del 
limitado nuestras conversaciones, pero había nacido en él un celo ardiente en la exploración de las numerosas cavernas de la región, que dio lugar rápidamente a múltiples e importantes descubrimientos, en los que participó el padre lazarista Lorenzo Sierra. Ambos fueron, hasta su muerte, unos amigos y colaboradores admirables» 64 .

Alcalde del Río se convirtió entonces en el más importante de los cooperantes españoles de Breuil. El intercambio epistolar entre ambos era constante, aunque, desgraciadamente, sólo poseemos las cartas del primero. Los sucesivos hallazgos de Alcalde y Sierra, fueron motivo de viajes de Breuil en 1904, 1906 y años siguientes. En julio de 1909, el príncipe Alberto quiso conocer las cuevas principales. El abate Breuil explicó así aquel viaje:

«El 10 de julio de 1909, nos informó que se ponía rumbo a Santander con su yate de trabajo, el "Princesse Alice". Obermaier tenía que venir de Viena ( $y$ en aquel tiempo no habia aviones) y las pequeñas vías férreas de la España del Norte no tienen más que trenes tardígrados. Cuando llegamos a Santander, el 19 de julio de 1909, la bonita silueta del "Princesse Alice" se destacaba en medio de la rada, objeto de la curiosidad de los habitantes de la ciudad. Fuimos enseguida a bordo para fijar los planes: fueron previstas tres excursiones, Covalanas al Este en las fronteras de Vizcaya; Castillo (Puente Viesgo) gran caverna con arte y con excavaciones iniciadas el año precedente; por último, Altamira, la "Capilla Sixtina" del arte cuaternario. Algún iluminado del país quiso arrastrar al príncipe a otra cueva en Suances, no lejos de Altamira, "más bella, decían, que ésta", pero desconfiando el príncipe me envió allí era una cueva recientemenre adornada con estúpidas figuras. Pero en el Palacio contiguo se había preparado, con gran lujo de cristalería, un champaña en honor del visitante principesco y su séquito. Fui el único, y de muy mal humor, en vaciar una copa. Nuestras tres excursiones, realizadas bajo la gula de Obermaier y de mí mismo, impresionaron vivamente a su Alteza, y fue con pesar que abandonó esta rierra de España a la que le unían tantos recuerdos de juventud. El 25 de julio, el "Princesse Alice" se hacía a la mar" ${ }^{65}$.

Las carpetas de calcos y descripciones realizados por el trío Alcalde/Sierra/Breuil iban creciendo y, pensando que se conocía lo esencial de los yacimientos cantábricos con arte, se quiso publicar un volumen parejo al de Altamira. El resultado fue la aparición, en 1911, de Les cavernes

mismo año). Amplia recensión de $\mathrm{H}$. Breult, "Nouvelles découvertes dans la province de Santander", L'Anthropologie, XVII, 1906, págs. 143-149.

64 Del discurso del abate Breuil en la aperura del Congreso de la UISPP en Madrid. (A. BeltRán, ed.), Congresos internacionales de Ciencias Prehistóricas y Protohistóricas, Actas de la IV sesión, Madrid, 1954, Zaragoza, 1956, pág. XVIII.

65 Fragmento de $\mathrm{H}$. BREulL, "Souvenirs sur le Prince Albert de Monaco et son oeuvre préhistorique", Bulletin de la Société Préhistorique Française, XLVIII, 1951, págs. 287-288. RIPOLL, EI abate Henri Breuil, citado, págs. 92-93 y 97-98. 


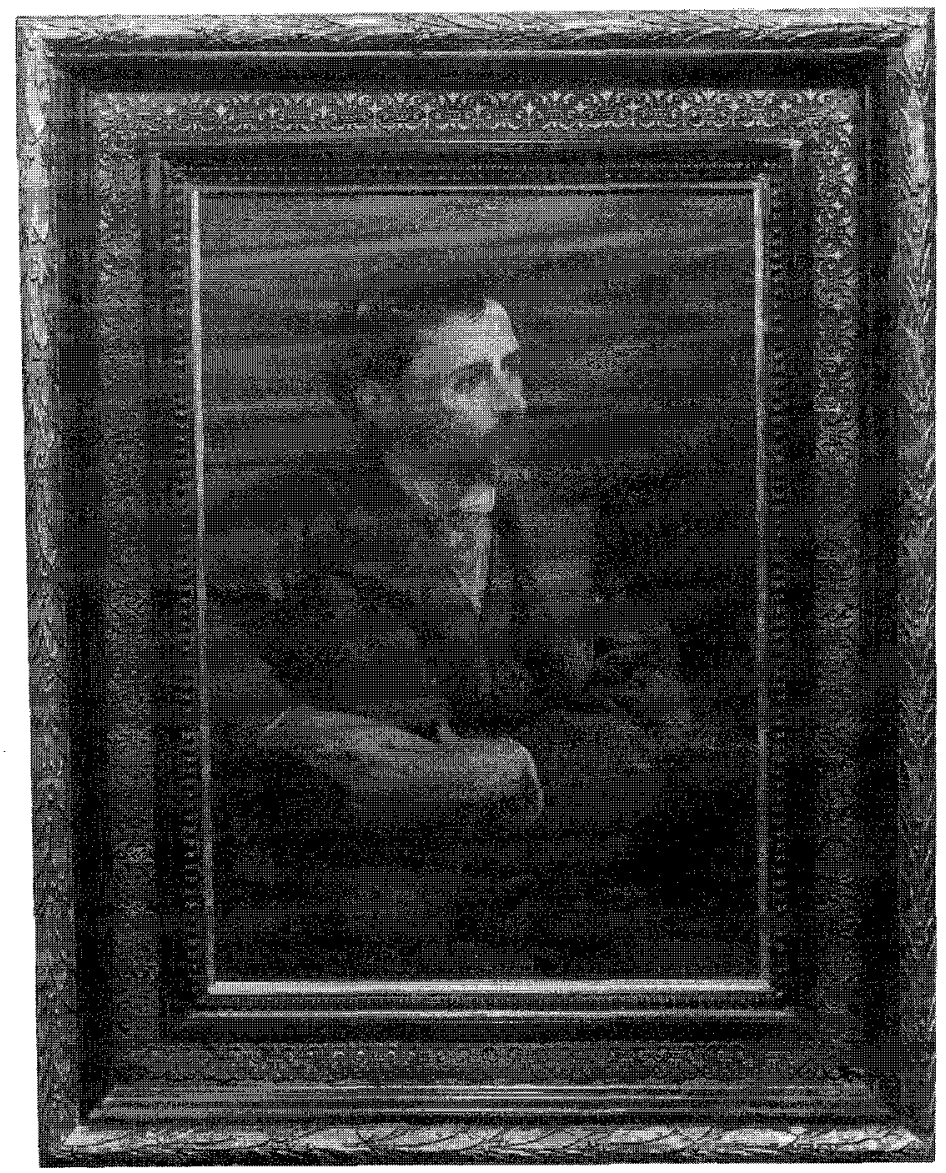

Don Hermilio Alcalde del Río (1866-1947), descubridor de El Castillo y otras cavernas con arte paleolítico (col. E.R.)

de la region cantabrique ${ }^{66}$. El enorme volumen ( $66 \mathrm{~kg}$. de peso!), contiene el estudio pormenorizado de dieciséis lugares con arte, además de aportar "complementos» sobre Altamira. Una parte esencial del mismo está dedicada a la cueva del Castillo. A continuación, por orden cronológivo, damos la lista de dichos yacimientos, indicando el autor y la fecha del descubrimiento, así como las páginas que a cada uno se refieren en dicho gran libro:

66 H. Alcalde del Rio; H. Breull y L. Sierra, les cavernes de la région cantabrique (Espagne), Mónaco, Imprimerie Vve. A. Chêne, 1911, VIII + 265 págs., 258 figs. y 100 láminas. 
1. Salitre (L. Sierra, 21 de julio de 1903; págs. 23-26).

2. Covalanas $(H$. Alcalde y L. Sierra, 11 de septiembre de 1903; págs. 14-22).

3. La Haza (H. Alcalde y L. Sierra, 13 de septiembre de 1903; págs. 11-14).

4. Hornos de la Peña (H. Alcalde, 27 de octubre de 1903; págs. 85111).

5. El Castillo (H. Alcalde, 3 de noviembre de 1903; págs. 112-193).

6. La Clotilde de Santa Isabel (H. Alcalde y H. Breuil, julio de 1904; págs. 40-46).

7. Venta de la Perra (L. Sierra, 16 de agosto de 1904; págs. 1-8).

8. Santián (L. Sierra, 12 de agosto de 1905; págs. 8-9).

9. Sotarriza (L. Sierra, 12 de agosto de 1906; págs. 8-9).

10. El Pendo (H. Alcalde, noviembre de 1906; págs. 35-39).

11. La Meaza (H. Alcalde, 11 de marzo de 1907; págs. 50-52).

12. El Pindal (H. Alcalde, abril de 1908; págs. 59-81).

13. El Quintanal (H. Alcalde, abril de 1908; págs. 81-84).

14. Mazaculos (H. Alcalde, abril de 1908; págs. 81-84).

15. La Loja $(\mathrm{H}$. Alcalde, H. Breuil y $\mathrm{M}$. Mengaud, 23 de agosto de 1908; págs. 53-59).

16. Aguas de Novales (H. Alcalde, febrero de 1909; pág. 46).

El recién fundado Institut de Paléontologie Humaine tuvo la región cantábrica como uno de los principales escenarios de su actividad. Destaca en este aspecto la gran excavación de la cueva del Castillo, dirigida por H. Obermaier que tenía como adjunto a Paul Wernert (1889-1972) ${ }^{67}$ y como directos colaboradores a Breuil y Alcalde. Además, en los trabajos participaron algunos de los más prestigiosos prehistoriadores jóvenes de la época, como P. Teilhard de Chardin (París), Barón A. Blanc (Roma), Miles Burkitt (Cambridge), J. Nelson (Nueva York), F. Birkner (Munich) y R. Mallet (París). Como es sabido a causa de los inmediatos acontecimientos bélicos, no se

67 E. Ripoll Perelló, "Necrología. Prof. don Paul Wernert (1889-1972)", Ampurias, 35, 1973, págs. 280-281. Se citarán más adelante algunos de sus trabajos en España. Su amplia bibliografía fue recogida por A. THEVENin, en Bulletin de la Société Préhistorique Française, 71, 1974, págs. 98-102. 


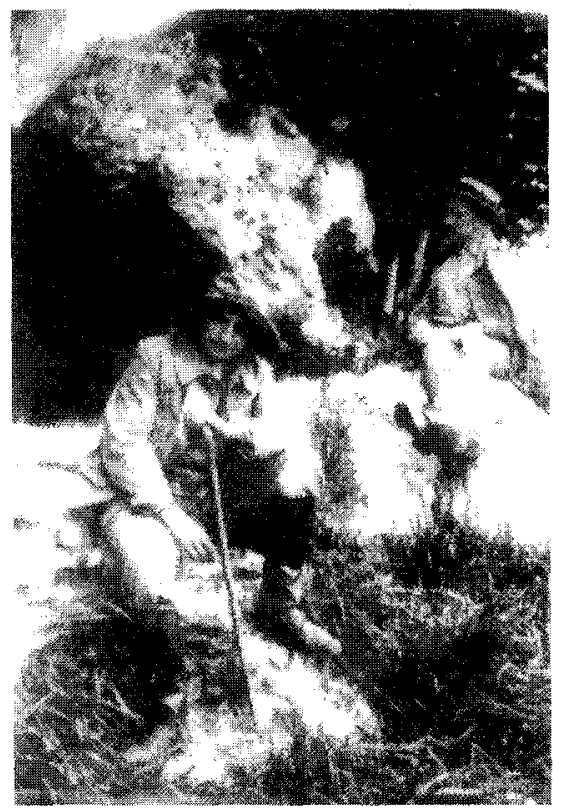

El abate H. Breuil y el Dr. R. C. Neison, en una de las entradas a la cueva de La Pasiega (Puente Viesgo) (fotografia de 19130 1914)

llegó a publicar el correspondiente estudio completo y los materiales permanecieron en la sede parisina del IPH hasta que, en 1973, por eficaz ges: tión de M. Almagro Basch, fueron llevados al Museo Arqueológico Nacional y posteriormente publicados (cf. la segunda parte de este trabajo).

En el mes de mayo de 1911, apenas iniciada la anual campaña de excavaciones en la cueva del Castillo, en un descando obligado por la inundación de la gran trinchera a causa de la lluvia, Obermaier y Wernert penetraron en una nueva cueva con arte en el mismo Monte. Su exploración fue completada por Alcalde del Río unos días después. La noticia del descubrimiento de la nueva cavidad -que pronto sería llamada La Pasiega- le fue dada a Breuil, que estaba en Andalucía, por Alcalde y por Obermaier. De la carta del primero (25 de mayo de 1911), entresacamos lo siguiente:

«El contenido en toda ella (lo que hasta aquí he podido apreciar) supera a Castillo, los caballos, ciervos y bisontes se encuentran por docenas, los tectiformes lo mismo. Los primeros en rojo, negro y ocre; los segundos en rojo. Abundan los grabados grandes y de reducidas proporciones, así también de grandes y pequeñas las pinturas, muchas de tintas esparcidas que resultan bellos monocromos, también con su contorno grabado. Hay galerías que a derecha e izquierda y en el techo están plenas de estas pinturas 
que dan aspecto de habitaciones decoradas... Lo más nuevo, y único caso hasta el presente de pictografías rupestres, es un conjunto que representa una verdadera inscripción o escritura pictográfica que corresponde indudablemente, a su época; aunque no la retengo mucho en la memoria, viene a ser algo así: [dibujo]... En resumen, la presente gráfica guarda estricta relación con la más vieja de Castillo, y con esta localidad ha estado en frecuentes relaciones o tratos, así también con las primeras fases de Altamira, donde hay motivos repetidos..." 68 .

En cuanto a la de $\mathrm{H}$. Obermaier (2 de junio de 1911), en francés el original, para completar la de Alcalde traducimos una parte:

«La historia de su descubrimiento es simple. Un obrero nos había indicado que conocía otra caverna en el "Picacho". Parados por el agua en nuestro vestíbulo, tomé la resolución de ir en seguida, invitando al señor Wernert a que me acompañara... Encontramos la cueva y entré en un laberinto asombroso. He aquí un plano muy simplificado [dibujo]... Encontré la primera vez la sala A: ciervas espléndidas, caballos muy hermosos, ciervos, etc.; panel magnífico de tectiformes. Dos días después vimos (Alcalde, Schmidt, Wernert y yo) la parte $B$, inscripción mística, muy original... Más tarde, Alcalde y yo, hemos buscado en la región de $\mathrm{C}$, sin poder entrar. Sorprendidos por un joven de la aldea de Villa Nueva (Hijas), nos enteramos de que se podía avanzar más. Dije que sí para no excitar la curiosidad del individuo y salí fuera. ¡He aquí una tercera sala! Al día siguiente, Alcalde y yo volvimos al lugar. Hermosas figuras de bisontes, caballos y tectiformes muy singulares. Yo encontré, además, el trono "sacerdotal" cuaternario, un trono especialmente adaptado. Todo es magnífico, pero ésta será otra buena tajada de trabajo..." ${ }^{69}$.

Requerida con urgencia la presencia de Breuil, el resultado de su estudio, hecho con toda rapidez, será la monografía titulada La Pasiega à Puente Viesgo, publicada en 1913 y firmada por Obermaier, Breuil y Alcalde del Río ${ }^{70}$.

\section{ANDALUCÍA, LEVANTE Y BATUECAS}

En el parágrafo anterior hemos explicado el descubrimiento de la caverna de La Pasiega en mayo de 1911. En aquel momento Breuil estaba en Andalucía, pero no sabemos exactamente dónde. Acaso su presencia

68 "Archivo E.R.", HAR, 25-5-1911. Las principales cartas de Alcalde del Río a Breuil las publicamos en RIPOLL Perelló, "Algunas cartas de Don Hermilio Alcalde del Río al Abate Henri Breuil», citado.

69 "Archivo E.R.», HO, 2-ó-1911. Como la anterior, publicadas completas en RIPOLL, El Abate Henri Breuil..., citado, págs. 100-105.

70 H. Obermaier, H. Breull y H. Alcalde del Rio, La Pasiega à Puente Viespo, Santander, Espagne, Mónaco, Imprimerie Vve. A. Chêne, 1913, VIII + 64 págs., 29 figs. y XXIX láminas. 
pueda relacionarse con la aparición en la revista británica The Saturday Review de unos escritos del coronel Willoughby Verner (1852-1922) ${ }^{71}$, residente en Algeciras. En ellos anunciaba el descubrimiento de una importante caverna con pinturas prehistóricas en el término de Benaojan, no lejos de la malagueña ciudad de Ronda, cavidad que luego se supo se llamaba La Pileta. El periodista Horace Sandars envió a su amigo Breuil aquellos textos y él mismo y la redacción de la revista le pusieron en relación con el militar inglés en noviembre de 1911. El 17 de dicho mes, Breuil se puso en contacto con Verner (carta que no se ha conservado) y éste le contesta el 26 de noviembre, en una carta con información sobre la cavidad y un breve perfil autobiográfico que traducimos a continuación:

«Querido señor Abate Breuil.- Yo he recibido su carta del pasado 17 con gran placer, y puedo asegurarle a $\mathrm{Vd}$. que me siento muy halagado al saber que se inieresa tanto por mis exploraciones de cuevas. Espero que Vd. entienda que no pretendo ser, como Vd. mismo, un hombre de ciencia. Yo soy meramente un soldado que ha dedicado sus horas de ocio al estudio de la Historia Natural, especialmente a la ornitología y a algunos viajes menores y exploración, según me lo permiten las circunstancias. De hecho, cualquier cosa de la vida silvestre me interesa.- Yo he leido su espléndido libro Les cavernes d'Altamira con el mayor interés, y nada me resultaría más satisfactorio que poderle acompañar a $\mathrm{Vd}$. y a alguno de sus colaborades a la caverna que he descubierto.- Yo espero también que $V \mathrm{~d}$. juzgue conveniente visitar Algeciras antes de mayo de 1912, fecha en que volveré a Inglaterra.En la actualidad yo soy casi un inválido. Hoy hace doce años de eso. Yo fuí terriblemente lacerado y herido en la Guerra de África del Sur, y tras varios años de sufrimiento tuve que abandonar el ejército. Por ello, ahora no puedo trepar con tanta agilidad como yo desearía y debo moverme sosegadamente. Ahora, como ha leído Vd., me dedico un poco al trabajo de las cuevas.Todos los dibujos que he visto son perfilados, le mando unos toscos trazos sacados de mis bocetos que le pueden interesar a Vd. como comparación con sus apuntes parecidos a un bisonte y dos series de mis apuntes que no se parecen en absoluto a un dibujo. He recibido su paquete de folletos y me siento todavía más obligado con Vd. por la gentileza que ha tenido mandándomelos.- Si hay algo en particular que Vd. quiera buscar en las cuevas, por favor hágamelo saber y yo haré lo que mejor sepa para cumplir sus instrucciones.- Sinceramente suyo.- Willoughby Verner» 72.

71 W. Verner había participado en la expedición de ayuda a Khartum (Sudán) y fue gravemente herido en la guerra de los boers, perdiendo una pierna. Se retiró a vivir a su posesión de "El Águila» (Algeciras). Las notas en dicha revista: 10, 23 y 30 de septiembre; 7, 14 y 21 de octubre de 1911. Después de la exploración: 19 y 26 de octubre de 1912. Su especialidad como militar era la topografía, pero su afición era la ornitología como reflejan sus notas y trabajos. E. RIPOLL PERELLó, «Abate H. Breuil y Coronel W. Verner: textos sobre la cueva de La Pileta», Actas del Congreso Internacional "El Estrecho de Gibraltar», Ceuta, 1987, Madrid, UNED, 1988, t. I, págs. 173-181, 2 figuras.

72 "Archivo E.R.", WV, 27-11-1911. Texto original inglés y facsimil de la primera parte en RIPOL, «Abate H. Breuil y Coronel W. Verner...», citado; Id., El Abate Henri Breuil..., citado, págs. 106-109. 
La expedición tuvo lugar en la primavera de 1912 (del 18 de marzo al 18 de abril). Sobre ella, Breuil escribió una síntesis preciosa, en la que se subraya el esfuerzo físico de $W$. Verner, la eficacia sobre el terreno de José Bullón Lobato y la ayuda de $\mathrm{H}$. Obermaier, P. Wernert y Juan Cabré ${ }^{73}$. El resultado de la no fácil exploración y los calcos correspondientes -tanto del arte paleolítico como del arte esquemático-, dieron lugar a un nuevo libro de la serie patrocinada por el príncipe de Mónaco, con el título La Pileta à Benaojan, firmado por H. Breuil, H. Obermaier y W. Verner ${ }^{74}$.

Los estudiosos de La Pileta se reencontraron en ella con pinturas de la vacies esquemática, pero ahora en el interior de una gran caverna y no al aire libre. Aunque haciendo un pequeño salto atrás en el tiempo, debemos ocuparnos ahora sobre los diversos descubrimientos del arte postpaleolítico peninsular, recordando asimismo lo que se ha dicho en el apartado de antecedentes.

A la nómina de personajes hasta ahora citados, en el primer decenio del siglo $x x$ se incorpora otro investigador eminente: el bajoaragonés Juan Cabré Aguiló (1882-1947) ${ }^{75}$. Cabré fue el descubridor en 1903 del primer lugar conocido de la facies levantina en el barranco de Calapatá (Cretas, Teruel). El hallazgo no fue anunciado hasta 1907 por Santiago Vidiella en una revista local ${ }^{76}$. El mismo año 1907 , o el siguiente, el párroco mosén Ramón Huguet encontró el friso pintado de Cogul (Lérida) que enseguida fue publicado por Ceferí Rocafort ${ }^{77}$. A Breuil, la noticia del hallazgo de

73 H. Breull, "Prefacio», en RIPOLL, El Abate Henri Breuil..., citado, págs. 15-17.

74 H. Breult, H. Obermaier y W. Verner, La Pileta à Benaojan, Málaga (Espagne), Mónaco, Imprimerie Vve. A. Chêne, 1915, VIII, 58 págs., 26 figs. y XXII láminas. Sobre la atribución cultural de La Pileta: E. RIPoll Pefelló, "La cronología relativa del 'Santuario' de la cueva de La Pileta y el arte solutrense", Homenaje al profesor Cayetano de Mergelina, Murcia, Universidad, 19611962, págs. 739-751, 6 figuras.

75 Cabré fue un arqueólogo activísimo, con más de un centenar de publicaciones en su haber. De sus trabajos sobre arte rupestre paleolítico y postpaleolítico nos ocuparemos en estas páginas. También hay que destacar sus aportaciones a la arqueología protohistórica e histórica. Su bibliografía fue reunida por A. BELTRÁN en Base (Cartagena), 1, 1945, págs. 58-73. Con motivo del centenario de su nacimiento se publicó (A. BELTRÁN, ed.), Juan Cabré Aguiló (18821982), encuentro de homenaje, Zaragoza, 1984, con trabajos de diversos autores sobre su labor.

76 S. VIDIELLA, "Las pinturas rupestres del término de Cretas», Boletín de Historia y Geografía del Bajo Aragón, 1, 1907, pág. 68. A pesar de su fecha hay que considerar como "precientífico» el artículo de E. MARCONELL, "Los toros de la Losilla", Miscelánea turolense (Madrid), 1892, no 9, pág. 160 y $n^{0} 10$, pág. 180, que se refiere a los bóvidos figurados en los abrigos de la serranía de Albarracín.

77 Ceferí Rocafort, "Les pintures rupestres de Cogul», Butlleti del Centre Excursionista de Catalunya, XVIII, marzo de 1908, n..$^{156}$, págs. 65-75. L. M. VIDAL, "Les pintures rupestres de Cogul», Anuari de l'Institut d'Estudis Catalans, 1908, págs. 544-550, figs. 3-7, lám. 6. 


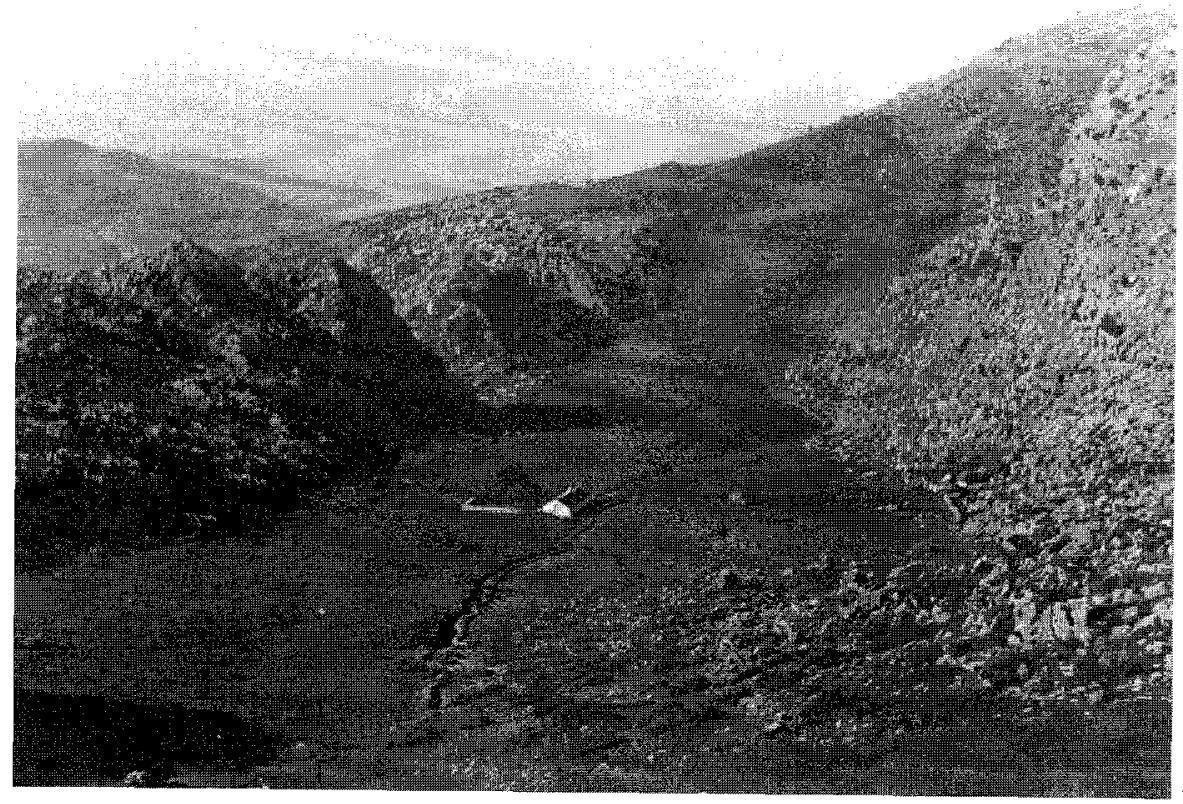

Vistas del cortijo de los Bullón desde la entrada a la cueva de La Pileta (Benaojan, Málaga) (foto E. Ripoll, 1956)

Calapatá le llegó por Alcalde del Río y probablemente desde Barcelona la de Cogul ${ }^{78}$.

En 1908, Breuil visitó ambos lugares. En Lérida fue atendido por Nicolás Arderieu, que le facilitó el viaje en tartana a Cogul y consiguió que le escribiera un artículo sobre las pinturas ${ }^{79}$. En Calaceite (Bajo Aragón) fue recibido por S. Vidiella y por J. Cabré y éste, por su facilidad para el dibujo y la pintura, se convirtió en un buen colaborador del abate, a cuyas órdenes trabajo algunos años. Resultado del viaje fue un artículo «fundacional» en L'Anthropologie ${ }^{80}$.

78 RIPOLL, El Abate Henri Breuil..., citado, págs. 111-116.

$79 \mathrm{H}$. BreulL, "Les pintures quaternaries de la roca de Cogul", Butlleti del Centre Excursionista de Lleyda, I, n² 10, octubre de 1908, págs. 10-13, 1 lám. en color.

$80 \mathrm{H}$. Breull y J. Cabré Aguilo, «Les peintures rupestres du basin inférieur de l'Ebre. I, Les rochers peints de Calapatá (Bas Aragon). II, Les fresques a l'air libre de Cogul, province de Lérida (Catalogne)", L'Anthropologie, XX, 1909, págs. 1-21, 9 figuras. La segunda parte es de Breuil solo y plantea ya el problema de la cronología, cuestión que trataremos en la segunda parte de este trabajo. 
Cabré, por encargo de Breuil, inició sus prospecciones con muy buenos resultados en la serranía turolense de Albarracín. Allí descubrió en 1909 los frisos grabados «históricos» de Peñalba de Villastar y los abrigos pintados de Callejón del Plou y Prado del Navazo. En 1911, al ir a copiar el arte de estos lugares con el abate, encontraron los grabados de la Fuente del Cabrerizo ${ }^{81}$.

Al mismo tiempo, por consejo del Marqués de Cerralbo ${ }^{82}$, inició sus exploraciones en el sudeste Pascual Serrano Gómez que, en 1910, descubrió la Cueva de la Vieja, en Alpera (Albacete), estudidada por él mismo con Breuil (que encontró la contigua cueva del Queso) y Cabré. El propio Serrano descubrió en 1912 el covacho pintado de La Tortosilla (Ayora, Valencia). Otros hallazgos de la facies levantina realizados por Breuil en sus continuos viajes de esta época por España, son los abrigos de Carasoles del Bosque (Alpera) y Cantos de la Visera (Arabí, Murcia) ${ }^{83}$.

En este mismo momento se producía la revalorización de la facies esquemática del arte rupestre peninsular. En el paragrafo $n .: 1$ del presente texto hemos hablado del artículo de Vicente Paredes sobre las pinturas de Las Batuecas publicado en Revista de Extremadura (1909). La noticia de la aparición de este trabajo le llegó a Breuil por su amigo Pierre Paris (1859-1931), a la sazón director del Institut d' Études Hispaniques de Burdeos y más tarde fundador y director de la Casa de Velázquez, en Madrid. Breuil, aunque conocía la existecnia del arte esquemático por el libro de Góngora, hasta aquellas fechas no había visto de dicho estilo más que las tres representaciones de la parte superior izquierda del friso de Cogul. El abate encargó a Cabré que leyera cuidadosamente el texto de Paredes y se trasladara a Las Batuecas para comprobar la existencia de las pinturas. El 13 de marzo de 1910, Juan Cabré escribía a Breuil una carta de la que extractamos lo siguiente:

"Primeramente tengo que manifestarle lo penosísimo del viaje, tárdase desde Madrid cerca de dos días, no viajando por la noche, para llegar a la Alberca en cuya jurisdicción están; llégase a Béjar con el tren, y desde Béjar se va a la Alberca con caballerías, invirtiendo en el viaje nueve leguas, y tres más

\footnotetext{
81 H. BREuli y J. Cabré Aguiló, 'Les peintures rupestres d'Espagne. III, Los Toricos de Albarracín (Teruel)», L'Anthropologie, XXII, 1911, págs. 641-648, 3 figs. y 1 lám. en color.

62 Enrique de Aguilera y Gamboa (1845-1922), protector de Cabré, arqueólogo él mismo y fundador del museo de su nombre.

83 H. Breull, Pascual Serrano Gómez y J. Cabré Agulló, «Les peintures rupestre d'Espagne. IV, Les abris del Bosque à Alpera (Albacete). V, Tortosilla à Ayora (Valence)", L'Anthropologie, XXIII, 1912, págs. 529-561, 13 figs. y una banda desplegable. H. BREUiL, «Les peintures rupestres d'Espagne. VI, Les abris peints du Monte Arabi, près Yecla (Murcie). VII, Nouvelles roches peintes de la région d'Alpera (Albacete). VIII, Les roches à figures naturalistes de la région de Vélez Blanco", L'Anthropologie, XXVI, 1915, págs. 313-336, 10 figuras. El nº VI con Miles Burkitt y el VIII con F. de Motos.
} 


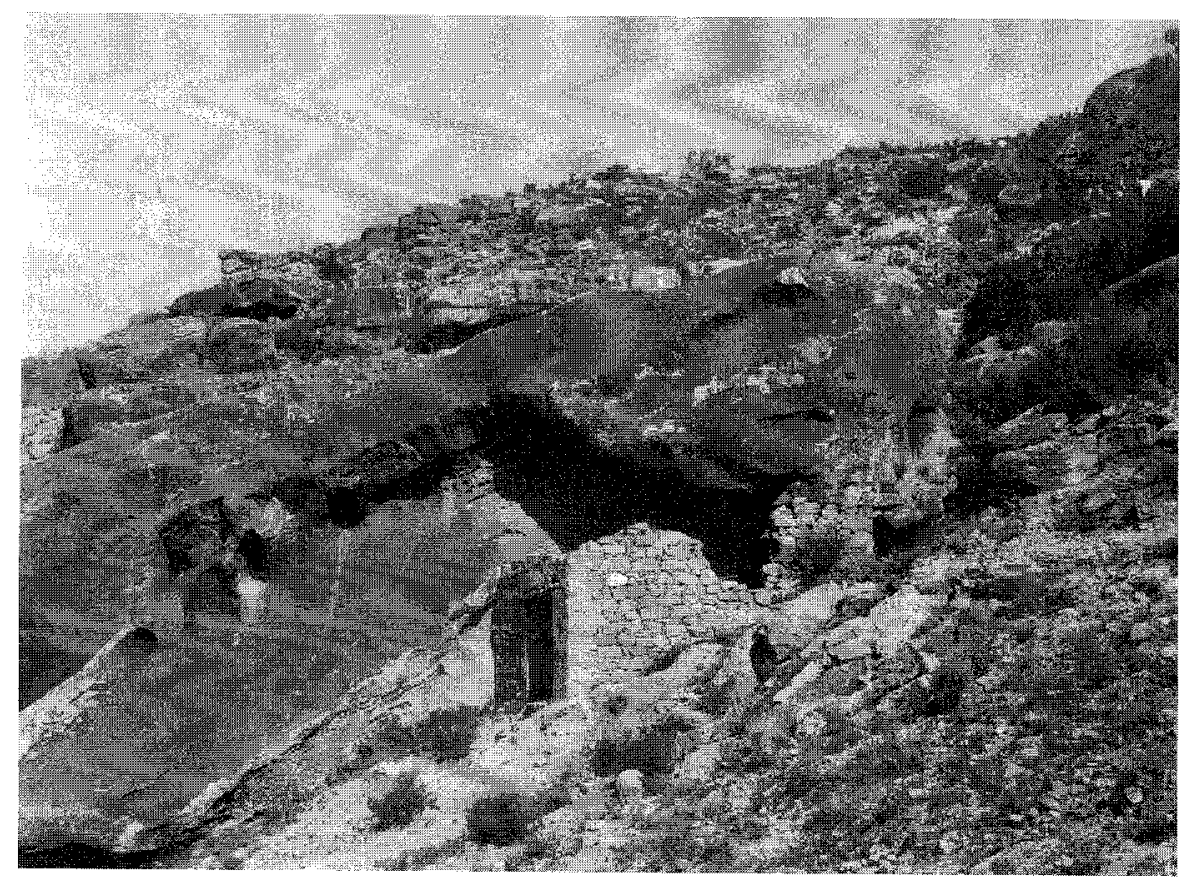

Abrigo de Cogul (Lérida), con el muro de protección construido poco después del descubrimiento y actualmente sustituido por un enrejado (foto E. Ripoll, 1951)

desde el puebo al convento de las Batuecas, sitio de las pinturas; país escabrosísimo, sin caminos, salvaje, en donde hoy día se perpetúan lobos y jabalíes.- Voy a contarle lo que vi; llevaba por guía las indicaciones del señor Vicente Paredes; dicho señor me hizo constar antes por carta que no conocía de vista las pinturas, sino por referencia. Por más que busqué no hallé nada de lo escrito por Paredes, pero sin embargo en la orilla opuesta lo primero que encontrar fue, en unas rocas, una pequeña figura en rojo, de animal felino, regularmente conservada, cerca una cabra en muy buen estado; todo esperanzado emprendí la rebusca de otras, y no tardé en copiar unos caballos que apenas se distinguían, y luego en otras rocas más y más pinturas, casi todo ello de puntos rojos, y pues quedé sorprendido de ver en un sitio estilizaciones humanas y animales en rojo, ocre, negro y blanco, y el asombro llegó a su apogeo cuando vi una roca llena de cabras pintadas, puntos, peces, etc., y en medio de toda esta composiciíon las estilizaciones de Cogul de los hombres matando ciervos, ídolo como el de Albarracín y puntos, todo ello en blanco. Son monumentos sagrados dedicados a una divinidad que no conocemos...” ${ }^{84}$.

84 "Archivo E.R.», JC, 13-03-1910. Esta y otras siete cartas de Cabré a Breuil sobre las Batuecas, precedidas de un comentario, en E. RIPOLL PERELLó, «Las pinturas rupestres de las 
La carta de Cabré era un acicate y para Breuil estaba llena de interrogantes. ¿De que se trataba? Inmediatamente el abate llegó a Madrid y durante dos semanas del mes de abril ambos se dedicaron a la exploración y estudio de los frisos pintados del fragoso valle. Por el motivo que luego se explicará, el estudio correspondiente no se publicó hasta el final de la guerra de 1914-1918 y solo firmado por Breuil ${ }^{85}$.

Por todo ello se imponía el conocimiento directo de los lugares señalados e ilustrados por Góngora en su libro pionero. En 1912, Breuil y Cabré, bajo la guía de Louis Siret (1860-1934), que les hizo conocer su descubrimiento de Lubrín (cerca de Cuevas de Vera, Almería), viajaron a Vélez Blanco para ver la Cueva de los Letreros y conocer al farmacéutico de dicha villa, Federico de Motos, que había encontrado otros lugares con pinturas y se convirtió en buen amigo y colaborador del abate ${ }^{86}$. Fueron luego a Jimena (Jaén) para estudiar las pinturas del abrigo de la Graja que en 1908 había publicado Manuel Gómez-Moreno (1870-1970) ${ }^{87}$. A continuación se trasladaron a Fuencaliente (Ciudad Real), para comprobar las noticias dadas por el Cura de Montoro en el siglo xvill como se ha expuesto, y que también recogió Góngora.

Se hacía evidente que era necesario planificar el estudio y realizar nuevas búsquedas. Para estas se reclutaron campesinos que eran expertos prospectores: Juan Llamas, en Vélez Blanco, captado por Motos; Tomás Pareja Luna y su hijo Faustino, en Fuencaliente; y José Mena en la región del estrecho de Gibraltar que ya trabajaba en las expediciones ornitológicas del coronel Verner. Además, Breuil realizó dos largas expediciones por Sierra Morena, de este a oeste. En la primera (1912) le acomparon Obermaier y Wernert; en la segunda (1913), Juan Cabré ${ }^{88}$. Para establecer

Batuecas: cartas de Don Juan Cabré al Abate Henri Breuil», Revista de Estudios Extremeños, LIII, 1997, págs. 399-410.

$85 \mathrm{H}$. Breuil, "Les peintures rupestres de la Péninsule Ibérique. IX, La vallée peinte des Batuecas (Salamanca)", L'Anthropologie, XXIX, 1918-1919, págs. 1-27, 20 figs. y Il láminas.

86 H. BREUIL y F. DE MOTOS, «Les roches à figures naturalistes de la région de Vélez Blanco», citado.

${ }^{87}$ Manuel Gómez-Moreno, «Pictografías andaluzas", Anuari de l'Institut d'Estudis Catalans, 1908, págs. 89-102, 13 figuras.

${ }_{88}$ De momento, para la historia de esta continua actividad hay que referirse a la enorme obra de conjunto de H. BreulL, Les peintures rupestres schématiques de la Péninsule lbérique, Lagny, Imprimerie de Lagny, 1933-1935. Vol. I, Au nord du Tage, 1933, 76 págs., 40 figs., 24 láms. y 2 hojas plegadas. Vol. III, Bassin du Guadiana, 1933, 192 págs., 50 figs., 42 láms. y 1 mapa. Vol. IIt, Sierra Morena, 1933, 125 págs., 54 figs. y 59 láminas. Vol. IV, Sud -Est et Est de l'Espagne, 1935, 166 págs., 90 figs. y 45 láminas. Anteriormente: H. Breull y H. Obermaier, "Travaux en Espagne. Fouilles du Castillo à Puente Viesgo (Santander). Novelles grottes ornées de la région cantabrique. Exploration rupestre en Sierra Morena. Région de Vélez Blanco. Prospection entre la privnce d'Almería et la Sierra Morena. Prospection de la région entre Valence, 


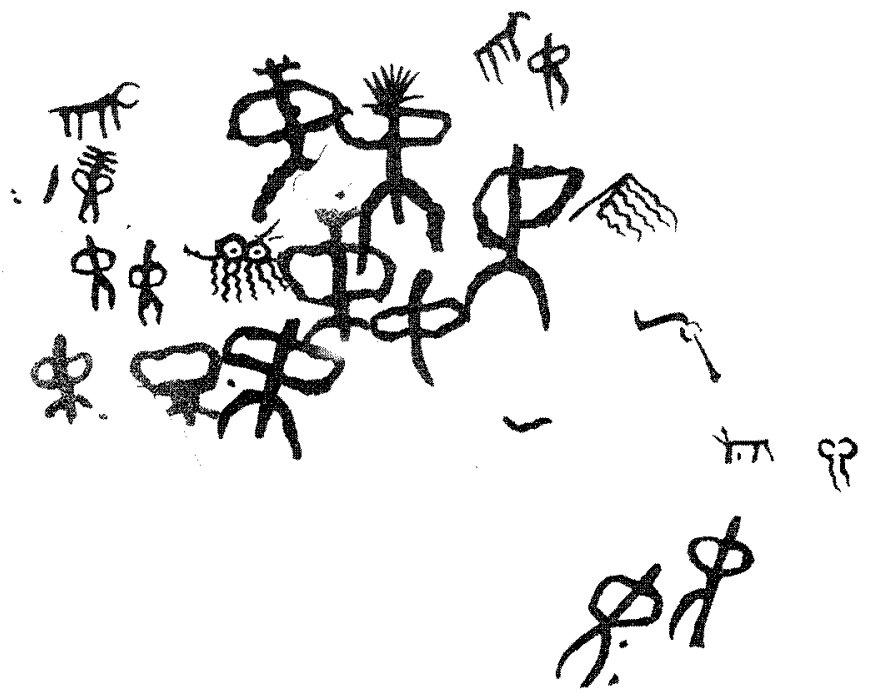

Parte del friso de pinturas esquemáticas de la cueva de La Granja (Jimena, Jaén). Según M. Gómez-Moreno (1908).

los itinerarios de forma concreta habrá que esperar que alguiene estudie los carnets de viaje del abate que se conservan en París.

En el panorama de estos estudios aparece en esta época otra eminente personalidad: Eduardo Hernández-Pachecho (1872-1965) ${ }^{89}$, que durante muchos años contó con la eficiente ayuda del dibujante Francisco Benítez Mellado. Para los trabajos de campo, ambos estaban adscritos a la recién fundada (1913) Comisión de Investigaciones Paleontológicas y Prehistóricas (CIPP, con sede en el Museo Nacional de Ciencias Naturales, Madrid). En este organismo también había encontrado un puesto Juan Cabré. El primer presidente de la Comisión fue el Marqués de Cerralbo que, en una de las primeras reuniones expuso que había conocido en la

\footnotetext{
Alicante et Ayora", L'Anthropologie, XXV, 1914, págs. 233-253, 15 figuras. H. BREUiL, W. VerNER y F. DE MOTOS, “Liste des localités rupestres étudiées de janvier à avril 1914", Institut Français d'Anthropologie, XXIV, 1914, págs. 79-81.

89 Hernández-Pacheco, fue catedrático de Geología de la Universidad de Madrid, promotor de los estudios de Prehistoria en nuestro país y uno de los fundadores de la Comisión de Investigaciones Paleontológicas y Prehistóricas que editó una importante serie de memorias. Además de las monografías que se irán citando, en los últimos años de su vida escribió una serie de libros de amplia síntesis. Para el tema que aqui se trata: E. HERnÁnDEZ-PACHECHO, Prehistoria del solar hispano, orígenes del arte pictórico, Madrid, Academia de Ciencias, 1959, 768 págs. y 578 figuras.
} 
Academia de la Historia la existencia de un covacho con notables pinturas prehistóricas en la serranía que mira a la Laguna de la Janda (Benalup de Medinasidonia, la antigua Casas Viejas, Cádiz). La primera nota de su descubrimiento la había dado el sacerdote gaditano Víctor Molina y la comunicación a la Academia el médico José Espinas. Inmediatamente viajaron al lugar Hernández-Pacheco y Cabré. Localizado y estudiado el Tajo de las Figuras, encontraron otros abrigos con pinturas esquemáticas en lugares cercanos a la depresión de La Janda. Los primeros resultados se expusieron en la sesión de la Sociedad Española de Historia Natural del 2 de julio de 1913. La monografía, redactada por Cabré, pero firmada por ambos, se publicó en 1914. Al propio tiempo se editaba la de las pinturas y grabados de Peña Tú (o Peñatu) (Llanes, Asturias) que Hernández-Pacheco y el Conde de la Vega del Sella habían encontrado ${ }^{90}$. Así, el arte esquemático estaba también presente en el extremo septentrional de la Península.

A comienzos de 1914, Breuil y Verner, con la colaboración de Miles Burkitt, estudiaron las pinturas del Tajo de las Figuras de La Janda y prospectaron con cuidado las sierras vecinas. Pero los resultados no se publicarían hasta unos años más tarde.

No podemos dejar de aludir a un hecho que afectó a estas investigaciones: la ruptura de la que había sido fructífera colaboración de Breuil y Cabré. Es probable que el hecho se hubiera originado después del viaje y estudio de Las Batuecas, como parece deducirse de una nota de Breuil ${ }^{91}$. También cabe ponerlo en relación con una cierta rivalidad existente entre investigadores franceses y españoles en el campo de la arqueología en general. Como se ha visto, ese mismo año 1913 Cabré estaba incorporado a la CIPP. Personalmente pensamos que esta ruptura no benefició en absoluto a los estudios de arte rupestre peninsular, aunque ambos hombres siguieron trabajando con ahinco. Acerca de la relación entre Breuil y Cabré el que suscribe escribió:

"Las relaciones entre ambos personajes tuvieron los altibajos correspondientes a dos hombres que se apreciaban, pero cuyos caracteres eran muy di-

90 J. CABRÉ y E. HeRnÁndez-PACHeCO, Avance al estudio de las pinturas prehistóricas del extremo sur de España (Laguna de la Janda), CIPP, mem. n² 3, Madrid, 1914, 35 págs., 6 figs. y XItI láminas. E. HERnÁndez-PACHECO, J. CABRÉ y CONDE dE la VEGA del. SELLA, Las pinturas prehistóricas de Peñatú, CIPP, mem. n² 2, Madrid, 1914, 25 págs,, 10 figs. y ll láminas. Ambas obras recensiones por $\mathrm{H}$. BREuIL en L'Anthropologie, XXIV, 1914, págs. 544-548, y en Revue Archéologique, XXIV, 1914 , págs. 342-345 y 345-347.

${ }_{91}$ H. BREUIL, Les peintures rupestres schématiques..., citado, t. I, nota de la pág. 2: «L'attitude de M. Cabré en 1913 n'a pas permis à notre collaboration de se poursuivre, et elle fut rompue par ordre exprés du prince Albert". 
ferentes. Pero la amistad y el aprecio se mantuvieron, como se comprobò en momentos muy dificiles y muchos años después, cuando Breuil tuvo que huir de su país a comienzos de la Segunda Guerra Mundial y llegó a España» ${ }^{92}$.

Aunque sea saltando algo el límite cronológico que para esta parte nos hemos impuesto, por su relación con los hechos y descubrimientos a que hemos hecho referencia sucintamente, es imprescindible señalar la aparición en 1915 del amplio libro de Juan Cabré titulado El arte rupestre en España ${ }^{93}$. En él se habla de forma lacónica, pero con ponderado respeto, de sus trabajos como colaborador del abate.

Todo aquel panorama de cooperación y pequeñas rivalidades quedó trágicamente afectado al estallar de forma casi inesperada la primera contienda mundial de 1914/1918. Suspendidas las excavaciones de la Cueva del Castillo, los acontecimientos arrastran a muchos de nuestros protagonistas: Obermaier, pacifista de corazón, pero oficialmente alemán, decide quedarse en España y encuentra refugio en la CIPP; Wernert, soldado francés y alsaciano; Teilhard de Chardin, camillero en primera línea; Verner, alejado de la contienda por su condición de inválido, pronto verá morir a su hijo y a su yerno en un combate naval; Burkitt, oficial inglés en las trincheras francesas, etc. En cuanto a Breuil, primero llamado a filas y luego declarado inútil para el servicio de armas, fue destinado como agregado al Servicio de Información Naval de la Embajada de Francia en Madrid. Pasará en España los tres años que quedaban de guerra, combinando su actividad oficial de continuos viajes, con los contactos con los amigos y los trabajos científicos.

En la Península, la neutralidad de los dos países, permite proseguir, con muy pocas limitaciones, las exploraciones y la publicación de sus resultados. Descubrimientos como el de la caverna con arte paleolítico de la Peña de Candamo (Asturias) por E. Hernández-Pacheco, o el del abrigo con arte postpaleolítico de Minateda (Albacete) por F. de Motos y $\mathrm{H}$. Breuil, son logros de aquel período que abrirán la segunda parte del presente trabajo.

92 RIPOLL, El Abate Henri Breuil..., citado, pág. 115

93 Juan CABRÉ AGUILó, El arte rupestre en España (regiones septentrional y oriental), prólogo del Marqués de Cerralbo, CIPP, memoria n 1, Madrid, 1915, 32+236 págs., 104 figs. y XXXI láminas. Breuil hizo una severe crítica del libro: H. BREUIL, "Algunas observaciones acerca de la obra de Juan Cabré titulada: El arte rupestre en España», Boletín de la Real Sociedad Española de Historia Natural, XVI, 1916, págs. 253-269 (manuscrito entre los papeles de Breuil que poseemos), texto repetido de manera aproximada en L'Anthropologie, XXVII, 1916, págs. 588-597. 